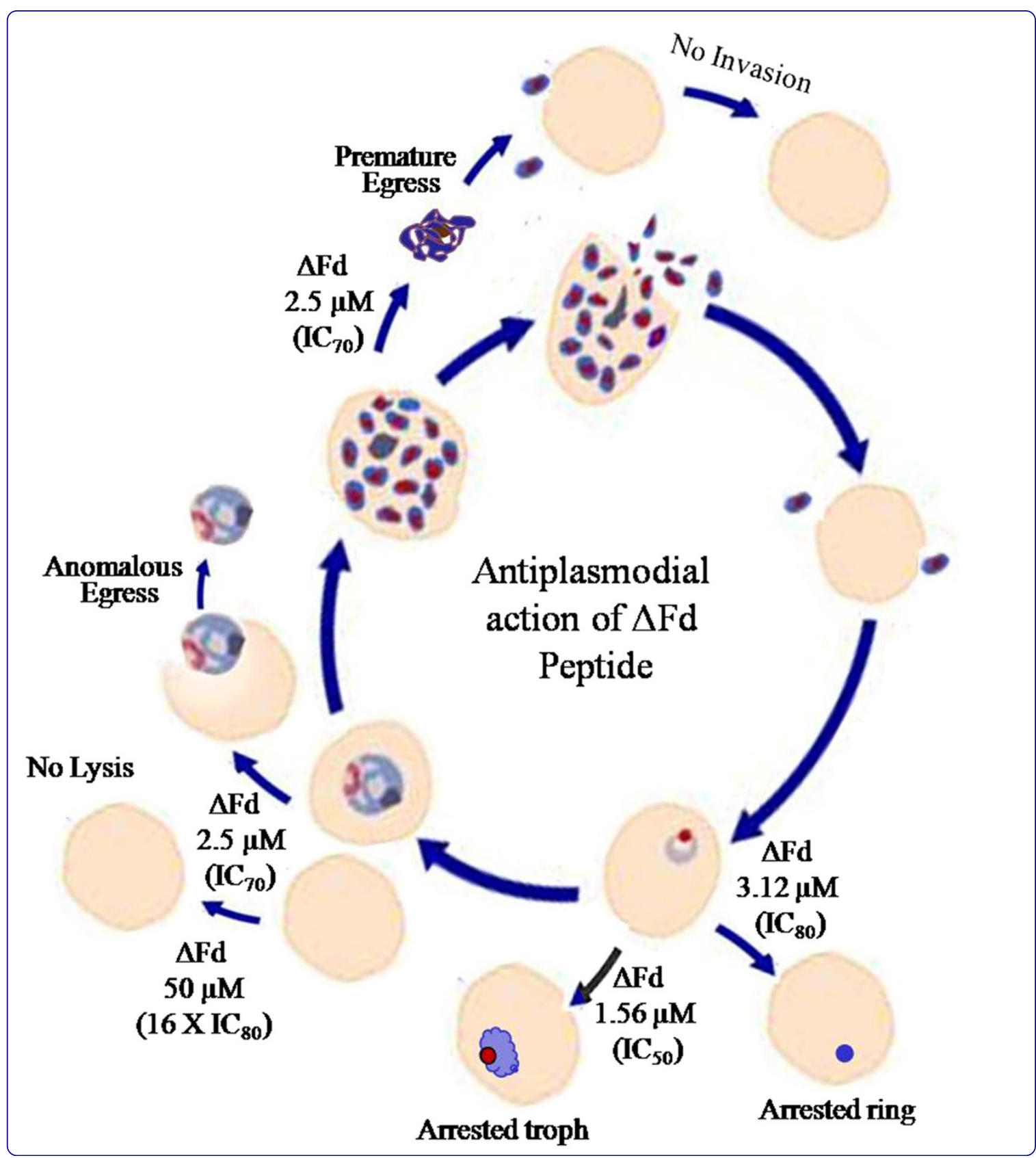

Anti-plasmodial action of de novo-designed, cationic, lysine-branched, amphipathic, helical peptides

Kaushik et al. 


\title{
Anti-plasmodial action of de novo-designed, cationic, lysine-branched, amphipathic, helical peptides
}

Naveen K Kaushik, Jyotsna Sharma and Dinkar Sahal

\begin{abstract}
Background: A lack of vaccine and rampant drug resistance demands new anti-malarials.

Methods: In vitro blood stage anti-plasmodial properties of several de novo-designed, chemically synthesized, cationic, amphipathic, helical, antibiotic peptides were examined against Plasmodium falciparum using SYBR Green assay. Mechanistic details of anti-plasmodial action were examined by optical/fluorescence microscopy and FACS analysis.

Results: Unlike the monomeric decapeptides $\left\{\left(\mathrm{Ac}-\mathrm{GXRKXHKXWA-NH_{2 }}\right)(\mathrm{X}=\mathrm{F}, \Delta \mathrm{F})\left(\mathrm{Fm}, \Delta \mathrm{Fm} \mid \mathrm{C}_{50}>100 \mu \mathrm{M}\right)\right\}$, the lysine-branched,dimeric versions showed far greater potency $\left\{\mathrm{IC}_{50}(\mu \mathrm{M}) \mathrm{Fd} 1.5, \Delta \mathrm{Fd} 1.39\right\}$. The more helical and proteolytically stable $\Delta \mathrm{Fd}$ was studied for mechanistic details. $\Delta \mathrm{Fq}$, a $\mathrm{K}-\mathrm{K}_{2}$ dendrimer of $\Delta \mathrm{Fm}$ and $(\Delta \mathrm{Fm})_{2}$ a linear dimer of $\Delta \mathrm{Fm}$ showed $\mathrm{IC}_{50}(\mu \mathrm{M})$ of 0.25 and 2.4 respectively. The healthy/infected red cell selectivity indices were $>35(\Delta \mathrm{Fd})_{1}>20(\Delta \mathrm{Fm})_{2}$ and $10(\Delta \mathrm{Fq})$. FITC- $\Delta \mathrm{Fd}$ showed rapid and selective accumulation in parasitized red cells. Overlaying DAPI and FITC florescence suggested that $\Delta$ Fd binds DNA. Trophozoites and schizonts incubated with $\Delta \mathrm{Fd}(2.5 \mu \mathrm{M})$ egressed anomalously and Band-3 immunostaining revealed them not to be associated with RBC membrane. Prematurely egressed merozoites from peptide-treated cultures were found to be invasion incompetent.
\end{abstract}

Conclusion: Good selectivity (>35), good resistance index (1.1) and low cytotoxicity indicate the promise of $\Delta \mathrm{Fd}$ against malaria.

Keywords: Anomalous egress, Anti-plasmodial peptides, De novo peptide design, Kinetics of peptide uptake, Peptide binding to DNA, Plasmodium falciparum

\section{Background}

The devastating diseases caused by protozoan parasites are a major burden of the tropics, and in particular, Plasmodium falciparum, the causative agent of falciparum malaria, creates a serious public health problem in many areas of the densely populated developing world. The widespread resistance of $P$. falciparum to chloroquine (CQ), which has spread from Asia to Africa, has rendered the drug ineffective against the most dangerous Plasmodium strain in many affected regions of the world. Unfortunately, CQ-resistance is associated with cross-resistance to other quinoline drugs, such as quinine

\footnotetext{
* Correspondence: dinkar@icgeb.res.in

Malaria Research Group, International Centre for Genetic Engineering and Biotechnology, Aruna Asaf Ali Marg, New Delhi 110067, India
}

and amodiaquine [1]. Plasmodium falciparum is genetically diverse and has multiple independent origins of mutations in genes that confer resistance to widely used anti-malarial drugs [2]. Left with just artemisinin to fight against malaria, Arata Kochi, Director of the Malaria Division at the World Health Organization, had felt compelled to say "if we lose artemisinin, we will no longer have an effective cure for malaria" [3]. However, most recently, alarming signs of clinical resistance against artemisinin, in the form of delayed parasite clearance, are being observed in the border between Cambodia and Thailand $[4,5]$. The challenge of designing an effective vaccine along traditional lines against malaria is that many P. falciparum proteins are highly polymorphic and their functions are redundant [6]. More than 200 million new malaria cases 
reported annually is a challenge [7] that underscores the urgent requirement for new drugs against malaria.

Peptides are an essential component of defence mechanism of all life forms and anti-microbial peptides are evolutionarily ancient biological weapons. Their widespread distribution throughout the living kingdom suggests that anti-microbial peptides may have served a fundamental role in the successful evolution of complex multi-cellular organisms [8]. Despite their ancient lineage, anti-microbial peptides have remained effective defensive weapons, defeating the general belief that bacteria, fungi and viruses can and will develop resistance to any conceivable substance. Among other differences, uniquely anionic charge on bacterial surface is a curious feature that distinguishes the prokaryotic bacteria from their eukaryotic counterparts [9]. Anti-microbial peptides gain selectivity from their ability to target this previously underappreciated 'microbial Achille's heel' [10-12]. Interestingly, a seminal feature of the malaria parasite-infected red cell is reflected in an altered asymmetry of lipid composition in its cell surface membrane. In contrast to the uninfected, healthy red cell, the malaria-infected red cell shows a translocation of the anionic phosphatidylserine from the inner leaflet to the outer leaflet of the bi-layer [13]. As a result, the FITC-Annexin negative, healthy red cell now turns to become FITC-Annexin positive [14]. Thus a Plasmodium-infected red cell seems to mimic the anionic surface charge that characterizes the bacterial cell surface. In principle, this is expected to make malaria-infected red cells become vulnerable to the action of anti-microbial peptides. Indeed, naturally occurring or modified peptides, such as dermaseptin [15], oligoacyllysine [16], cyclosporin A [17], cecropin A [18], NK-2 [14] and meucin [19], have been found to display in vitro anti-malarial activity. Some membrane-active, hydrophobic peptides of fungal origin have also been found to exhibit in vitro anti-malarial action [20]. However, many of these naturally occurring peptides suffer from drawbacks such as poor potency, stability and selectivity [21]. Therefore, in a bid to improve their performance, efforts are being made to engineer peptides in diverse ways with the aim of reducing their size, improving their stability against proteases and enhancing their selectivity [22-24]. The structure activity relationships of a series of de novo-designed, conformationallyconstrained helical, amphipathic, cationic peptides against bacteria have earlier been reported [25]. In the present work, the potent anti-plasmodial action of these peptides against both CQ-sensitive and CQ-resistant strains of $P$. falciparum are being reported. The results indicate that a lysine-branched, dimeric peptide $\Delta \mathrm{Fd}$, which is highly potent $\left(\mathrm{IC}_{50} 1.39 \mu \mathrm{M}\right)$ across CQ-sensitive and CQ-resistant strains Resistance Index $\left(\mathrm{IC}_{50} \mathrm{CQ}\right.$ resistant strain/ $\mathrm{IC}_{50}$ CQ sensitive strain)1.1\} of $P$. falciparum, fairly selective against parasitized red blood cells $\left\{\right.$ Selectivity Index $\left(\mathrm{HC}_{50}\right.$
URBC/IC 50 P. falciparum) $>35$ ) and fairly non toxic to mammalian HeLa cells $\left(\mathrm{TC}_{50}>25 \mu \mathrm{M}\right)$, stalls parasite growth by causing arrest of ring stage parasite, anomalous egress of trophozoites and premature egress of schizonts that fail to produce invasion competent merozoites.

\section{Methods \\ Peptides}

Peptides $\Delta \mathrm{Fm},(\Delta \mathrm{Fm})_{2}, \Delta \mathrm{Fd}, \Delta \mathrm{Fq}, \mathrm{Fm}, \mathrm{Fd}, \mathrm{D}$-Lys- $\Delta \mathrm{Fd}$, prochitinase and E30 (Table 1) were synthesized by Fmoc chemistry-based, manual, solid-phase synthesis. Didehydrophenylalanine $(\Delta \mathrm{F})$ was chosen since it is a conformationally-constrained amino acid residue with a proven reputation to confer helical character to peptides. FITC derivatizations of $(\Delta \mathrm{Fm})_{2}$ and $\Delta \mathrm{Fd}$ were done after linking aminohexanoic acid to the $\mathrm{N}$ terminus. Peptides were purified to $>95 \%$ homogeneity by RPHPLC and characterized by mass spectroscopy and circular dichroism as described previously [25]. Chromatographic and mass spectral characterization is given as follows: RPHPLC profiles of control peptides prochitinase, E30 and bovine insulin (Additional file 1); $\Delta \mathrm{Fm}$ and $\Delta \mathrm{Fd}$ (Additional file 2) Electro Spray Mass Spectroscopy (ESMS) profiles of prochitinase, E30 and bovine insulin (Additional file 3); ESMS profiles of $\triangle \mathrm{Fm}$ and $\triangle \mathrm{Fd}$ (Additional file 4); MALDI of $(\triangle \mathrm{Fm})_{2}$ (Additional file 5), RPHPLC and mass spectral data for $\triangle \mathrm{Fq}$ (Additional file 6) and ESMS profiles of Fm, D-Lys- $\Delta \mathrm{Fd}$ and Fd (Additional file 7). Peptides corresponding to prochitinase, E30 (a 30 residues-long peptide from Hepatitis E virus ORF3) (synthesized and characterized in house) and bovine insulin (Sigma) were used as controls in experiments on $\Delta \mathrm{Fd}$ mediated selective haemolysis of infected red cells. FITC-Insulin (Sigma) was used as control in experiments done to study the uptake of FITC tagged $(\Delta \mathrm{Fm})_{2}$ and $\Delta \mathrm{Fd}$ by Plasmodiuminfected RBCs.

\section{In vitro cultivation of Plasmodium falciparum}

Chloroquine-sensitive (3D7) and CQ-resistant (Dd2 and INDO) strains of $P$. falciparum were maintained in continuous culture according to the method of Trager and Jensen [26] with minor modifications. Cultures were maintained in fresh group $\mathrm{O}^{\text {tve }}$ human erythrocytes suspended at $4 \%$ haematocrit in complete medium $\{16.2 \mathrm{~g} / \mathrm{L}$ RPMI 1640 containing $25 \mathrm{mM}$ HEPES, $11.11 \mathrm{mM}$ glucose (Gibco), 0.2\% sodium bicarbonate (Sigma), 0.5\% Albumax I (Gibco), $45 \mu \mathrm{g} /$ litre hypoxanthine (Sigma) and $50 \mu \mathrm{g} / \mathrm{litre}$ gentamicin (Gibco)\} and incubated at $37^{\circ} \mathrm{C}$ under a gas mixture $5 \% \mathrm{O}_{2}, 5 \% \mathrm{CO}_{2}$, and $90 \% \mathrm{~N}_{2}$. Every day, the spent medium was replaced by fresh complete medium to propagate the culture. For INDO strain in culture medium, albumax was replaced by $10 \%$ pooled human serum (Innovative Research) as suggested by MR4 [27]. Parasitaemia was monitored by microscopic examination of Giemsa-stained 
Table 1 In-vitro blood stage antiplasmodial activities, resistance and selectivity indices of peptides against different strains of $\boldsymbol{P}$. falciparum

\begin{tabular}{|c|c|c|c|c|c|c|}
\hline \multirow[t]{2}{*}{ Peptides } & \multirow[t]{2}{*}{ Peptide Sequence and design } & \multicolumn{3}{|c|}{$\mathrm{IC}_{50} P$. falciparum $(\mu \mathrm{M})$} & \multirow{2}{*}{$\frac{\text { Resistance index }}{\mathrm{IC}_{50} \mathrm{Dd} 2 / \mathrm{IC} \mathrm{C}_{50} 3 \mathrm{D} 7}$} & \multirow{2}{*}{$\begin{array}{c}\mathrm{HC}_{50} \text { URBC } \\
\mu \mathrm{M}\end{array}$} \\
\hline & & $3 \mathrm{D} 7$ & Dd2 & INDO & & \\
\hline $\mathrm{Fm}$ & Ac-GFRKFHKFWA-NH ${ }_{2}$ & $>100$ & $>100$ & & - & $>100$ \\
\hline$\Delta \mathrm{Fm}$ & Ac-G $\Delta$ FRK $\Delta$ FHK $\Delta$ FWA- $\mathrm{NH}_{2}$ & $>100$ & $>100$ & - & - & $>100$ \\
\hline$\Delta \mathrm{Fd}$ & 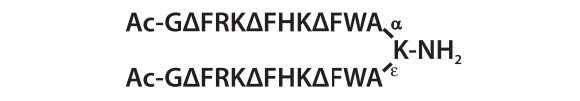 & $1.39 \pm 0.1$ & $1.6 \pm 0.09$ & $1.5 \pm 0.075$ & 1.15 & $>50(>35)^{*}$ \\
\hline D-Lys- $\Delta \mathrm{Fd}^{* *}$ & 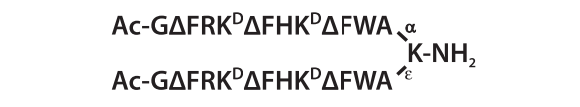 & $1.8 \pm 0.07$ & - & - & - & $>50(>27)$ \\
\hline $\mathrm{Fd}$ & $\begin{array}{l}\text { Ac-GFRKFHKFWA }{ }^{\alpha}{ }_{\varepsilon}^{\alpha}-\mathrm{NH}_{2} \\
\text { Ac-GFRKFHKFWA }\end{array}$ & $1.5 \pm 0.08$ & - & - & - & $>50(>33)$ \\
\hline$(\Delta \mathrm{Fm})_{2}$ & Ac-G $\Delta \mathrm{FRK} \Delta \mathrm{FHK} \Delta \mathrm{FWAAG} \Delta \mathrm{FRK} \Delta \mathrm{FHK} \Delta \mathrm{FWA}-\mathrm{NH}_{2}$ & $2.4 \pm 0.15$ & $2.5 \pm 0.13$ & - & 1.04 & $>50(>20)$ \\
\hline$\Delta \mathrm{Fq}$ & 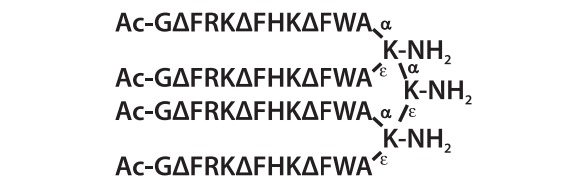 & $0.25 \pm 0.02$ & - & - & - & $2.5 \pm 0.13(10)$ \\
\hline Prochitinase & EEPHKAASAEGKK & $>40$ & - & - & - & $>40$ \\
\hline E30 & NPPDHSAPLGATRPSAPPLPHVVDLPQLGP & $>40$ & - & - & - & $>40$ \\
\hline Insulin & FVNQHLCGSHLVEALYLVCGERGFFYTPKA & $>40$ & - & - & - & $>40$ \\
\hline Artemisinin & & 0.015 & 0.016 & 0.015 & 1 & \\
\hline Chloroquine & & 0.04 & 0.16 & 0.5 & 4 & \\
\hline
\end{tabular}

${ }^{*}$ Hemolytic Selectivity index $\left(\mathrm{HC}_{50} \mathrm{URBC} / \mathrm{IC}_{50} \mathrm{Pf} 3 \mathrm{D} 7\right)$ is shown in parenthesis, ${ }^{* *}: \mathrm{K}^{\mathrm{D}}$ refers to Lysine of $\mathrm{D}$ configuration. Values of standard deviation given as \pm are based on three independent observations.

blood smears. Synchronized ring stage parasite was obtained by $5 \%$ sorbitol treatment [28]. Trophozoites and schizont-stage parasites were enriched by using Percoll gradient [29].

\section{Drug dilutions}

Stock solutions of peptides and CQ were prepared in water (milli-Q grade) while artemisinin stock solution was in dimethyl sulphoxide (DMSO). All stocks were then diluted with culture medium to achieve the required drug concentrations. The concentration of peptide solution in water was based on $A_{280}\left[\epsilon\left(\mathrm{M}^{-1} \mathrm{~cm}^{-1}\right)\right.$ $\Delta \mathrm{F}$ (didehydrophenylalanine) 19,000, W (Tryptophan) 5,000)]. Thus $\epsilon_{280}$ were 62,000, 124,000, 124,000 and 248,000 for $\Delta \mathrm{Fm},(\Delta \mathrm{Fm})_{2}, \Delta \mathrm{Fd}$ and $\Delta \mathrm{Fq}$ respectively. The concentration of FITC-peptides was based on $\mathrm{A}_{495}$ $\left[\epsilon\left(\mathrm{M}^{-1} \mathrm{~cm}^{-1}\right)\right.$ FITC 77,000 for $(\Delta \mathrm{Fm})_{2}$ with one FITC and 154,000 for $\Delta \mathrm{Fd}$ with two FITC per molecule]. Drugs and peptides solutions were placed in 96-well flat bottom tissue culture grade plates (Corning).

\section{Assay for anti-plasmodial activity}

For drug screening, SYBR green I based fluorescence assay was used as described previously by Smilkstein et al. [30]. Sorbitol synchronized ring stage parasites (haematocrit: $2 \%$, parasitaemia: $1 \%, 100 \mu \mathrm{l}$ ) under normal culture conditions were incubated in the absence or presence of increasing concentrations of peptides in water. CQ and artemisinin were used as positive controls. Vehicle control $0.4 \%$ DMSO (which was found to be non-toxic to parasite) was used in case of artemisinin. After $48 \mathrm{hr}$ of incubation $100 \mu \mathrm{l}$ of SYBR Green I buffer [0.2 $\mu$ l of 10,000 X SYBR Green I (Invitrogen) per ml of lysis buffer $\{$ Tris (20 mM; pH 7.5), EDTA (5 mM), saponin (0.008\%; wt/vol), and Triton X-100 (0.08\%; $\mathrm{vol} / \mathrm{vol})\}$ ] was added to each well, mixed twice gently 
with multi-channel pipette and incubated in dark at $37^{\circ} \mathrm{C}$ for $1 \mathrm{~h}$. Fluorescence was measured with a Victor fluorescence multi-well plate reader (Perkin Elmer) with excitation and emission wavelength centred at 485 and $530 \mathrm{~nm}$, respectively. Fluorescence counts for CQ $(0.1 \mu \mathrm{M}$ for 3D7, $1 \mu \mathrm{M}$ for INDO) were subtracted from counts in each well. The fluorescence counts were plotted against the drug concentration and $\mathrm{IC}_{50}$ (the $50 \%$ inhibitory concentration) was determined by analysis of dose-response curves. Results of the above mentioned fluorescencebased assay were validated microscopically by examination of Giemsa-stained smears of peptide-treated parasite cultures. Statistical significance of relative potencies of peptides was determined by student's $T$ test.

\section{In vitro stage dependence of action}

Stage specificity of action of $\Delta \mathrm{Fd}$ on the parasite's blood stage life cycle was determined by microscopic analysis of the effect of $\Delta \mathrm{Fd}$ on each of the three stages (ring, trophozoite and schizont) of the parasite life cycle. Synchronized stages were obtained by sorbitol-mediated synchronization repeated thrice (synchronization 1, medium washed, incubation for $3 \mathrm{hr}, 37^{\circ} \mathrm{C}$, synchronization 2 , medium washed and culture allowed to grow in complete medium for $48 \mathrm{hr}$. At this stage the culture was synchronized a third time to obtain highly synchronized ring stage culture). This culture was grown for $24 \mathrm{hr}$ and $38 \mathrm{hr}$ to obtain trophozoite and schizont stage cultures respectively. Both trophozoite and schizont enriched cultures were subjected to Percoll gradient centrifugation to obtain highly purified parasites of specific stages. Giemsa-stained smears were microscopically observed over 2,000 RBCs to obtain differential counts.

Cultures (1\% parasitaemia, $2 \%$ haematocrit) at each of the above mentioned stages were seeded in 96-well plates containing different concentrations of $\Delta \mathrm{Fd}$ and the plates incubated for $12 \mathrm{~h}$ (schizont), $24 \mathrm{~h}$ (trophozoite) and $48 \mathrm{~h}$ (ring) under standard culture condition. Smears were drawn, Giemsa-stained and analysed microscopically. Stage-specificity of action was assessed by observing the stage transitions in drug-treated samples against untreated controls.

\section{Cytotoxic activity of $\Delta \mathrm{Fd}$ on HeLa cells using MTT assay}

The cytotoxic effects of $\Delta \mathrm{Fd}$ on mammalian cells was assessed by functional assay as described [31] using HeLa cells cultured in RPMI containing 10\% fetal bovine serum, $0.21 \%$ sodium bicarbonate (Sigma) and $50 \mu \mathrm{g} / \mathrm{mL}$ gentamycin (complete medium). Briefly, cells $\left(10^{4}\right.$ cells/ $200 \mu \mathrm{l} /$ well) were seeded into 96- well flat-bottom tissue culture plates in complete medium. Peptide solutions were added after $24 \mathrm{hr}$ of seeding and incubated for $48 \mathrm{hr}$ in a humidified atmosphere at $37^{\circ} \mathrm{C}$ and $5 \% \mathrm{CO}_{2}$. DMSO (as positive inhibitor) was added at $10 \%$. Twenty microlitres of a stock solution of MTT $(5 \mathrm{mg} / \mathrm{mL}$ in $1 \mathrm{X}$ phosphate buffered saline) was added to each well, gently mixed and incubated for another $4 \mathrm{hr}$. After spinning the plate at $1500 \mathrm{rpm}$ for $5 \mathrm{~min}$, supernatant was removed and $100 \mu \mathrm{l}$ of DMSO (stop agent) was added. Formation of formazon was read on a microtiter plate reader (Versa max tunable multi-well plate reader) at $570 \mathrm{~nm}$. The $50 \%$ cytotoxic concentration $\left(\mathrm{TC}_{50}\right)$ of drug was determined by analysis of dose-response curves.

\section{Haemolysis assay}

Selectivity of haemolysis by peptides for infected erythrocytes (PRBC) vs uninfected erythrocytes (URBC) was examined by incubating the test molecules with URBCs and PRBCs respectively in phosphate-buffered saline (PBS). Briefly, fresh RBCs were spin washed (1600 RPM; 5 min) three times in PBS and re-suspended in PBS at $2 \%$ haematocrit. A $100 \mu \mathrm{l}$ suspension was added to 96-well plate containing the peptides at different concentrations. PBS alone (for baseline values) and 0.4\% Triton X-100 in PBS (for 100\% haemolysis) were used as controls. After incubation at $37^{\circ} \mathrm{C}$ for $3 \mathrm{hr}$, the samples were centrifuged and supernatant was used to determine the haemolytic activity measured in terms of haemoglobin release as monitored by $\mathrm{A}_{415}$. Triton-treated control samples were diluted 10 -fold before reading absorbance. Base line value (PBS control, $<0.3 \%$ of the triton value) was subtracted from each data point. Percent haemolysis has been expressed with reference to $100 \%$ haemolysis value assigned to positive control (triton X 100 treated RBCs). To study haemolytic susceptibility of parasitized cells, URBCs were replaced with varying percentages (10\% and $20 \%)$ of mixed stage parasitized cells. Three different control peptides (insulin prochitinase and E30, Table 1) were used to find whether there was specificity in the selective haemolytic action of $\Delta \mathrm{Fd}$. Haemolysis of parasitized erythrocytes was also monitored microscopically by examining the Giemsa-stained smears. Parasitaemia of $\Delta \mathrm{Fd}$ treated and untreated cultures were microscopically counted for ring, trophozoite and schizont stages respectively. Susceptibility of different stages was compared with corresponding untreated control cultures.

\section{Fluorescence microscopic imaging}

To probe mechanistic details of $\Delta \mathrm{Fd}$-mediated, premature parasite egress, $P$. falciparum 3D7 culture (5\% parasitaemia, $2 \%$ haematocrit) was incubated without (control) or with $\Delta \mathrm{Fd}(12.5 \mu \mathrm{M})$ at $37^{\circ} \mathrm{C}$ for $3 \mathrm{hr}$ in a final volume of $100 \mu \mathrm{l}$ made with RPMI $(96 \mu \mathrm{l}$ RPMI $+4 \mu \mathrm{l}$ peptide solution).

Smears were processed as indicated: (a) flooded with $2 \%$ BSA/PBS $\left(1 \mathrm{hr}, 37^{\circ} \mathrm{C}\right)$, (b) washed and flooded $\left(1 \mathrm{hr}, 37^{\circ} \mathrm{C}\right)$ with monoclonal anti-band 3 antibody produced in mouse (Sigma) (1: 500 dilution in 1\% BSA/PBS), (c) PBS washed 
and flooded with CY3 labelled anti-mouse antibody (Sigma)(1: 500 dilution in 1\% BSA/PBS, $1 \mathrm{hr}, 37^{\circ} \mathrm{C}$ in dark), (d) PBS washed and flooded with DAPI (4, 6-diamidino-2phenylindole) (invitogen) $\left(500 \mathrm{ng} / \mathrm{ml}, 10 \mathrm{~min}, 37^{\circ} \mathrm{C}\right)$. After a final PBS wash the smears were observed under Nikon eclipse fluorescence microscope.

For studying peptide localization, $P$. falciparum cultures were individually incubated with FITC- $\Delta \mathrm{Fd}(2 \mu \mathrm{M})$, FITC$(\Delta \mathrm{Fm})_{2}(2 \mu \mathrm{M})$ or FITC-Insulin $(3 \mu \mathrm{M})$ a) alone and b) together with DAPI in complete medium at $37^{\circ} \mathrm{C}$ for $30 \mathrm{~min}$ and the cells were spin washed (1,600 RPM, 5 min) twice with $1 \mathrm{X}$ PBS to reduce background fluorescence. The cells were smeared on a glass slide, and fluorescence was visualized by using the respective filter settings for FITC and DAPI.

For studying the selectivity and route of transport of $\triangle F d$ into the red cell-resident malaria parasite, URBC and PRBC were incubated with FITC- $\Delta \mathrm{Fd}(4 \mu \mathrm{M})$ in parallel sets at $4^{\circ} \mathrm{C} v s$ at room temperature $\left(25^{\circ} \mathrm{C}\right)$ for specified times and spin washed (1,600 RPM, 2 min) with complete medium (3 X $200 \mu \mathrm{l}$ ). The cells were smeared on a glass slide and both bright field images and fluorescence images (using FITC filter) were captured at $100 \mathrm{X}$ magnification using Nikon eclipse fluorescence microscope. The software Adobe Photoshop was used to overlay the fluorescence image on the bright field image.

\section{Kinetics of peptide uptake}

Kinetics of FITC-labelled peptide uptake was studied using Flow cytometer (BD FACS callibur). FITC- $\triangle$ Fd
(3 $\mu \mathrm{M})$ was incubated for indicated time intervals with synchronized rings ( $\sim 7 \%$ parasitaemia, $2 \%$ haematocrit) and synchronized trophozoites ( $\sim 20 \%$ parasitaemia, $2 \%$ haematocrit) stage cultures in a total volume of $100 \mu \mathrm{l}$. Cells were spin washed $(1 \mathrm{~min})$ with $1 \mathrm{ml}$ PBS and samples injected into FACS.

\section{Results}

Inhibition of Plasmodium falciparum growth by peptides

The anti-plasmodial activities of the de novo-designed, synthetic peptides $\Delta \mathrm{Fm}, \mathrm{Fm}, \Delta \mathrm{Fd}$, D-Lys- $\Delta \mathrm{Fd}$, Fd, $(\Delta \mathrm{Fm})_{2}$ and $\Delta \mathrm{Fq}$ (Table 1 ), were determined by quantitative SYBR Green I based estimation of DNA replication after one developmental cycle $(48 \mathrm{hr})$ as a measure of growth (see Figure 1 for growth inhibition profiles of $\Delta \mathrm{Fm}$, $(\Delta \mathrm{Fm})_{2}, \Delta \mathrm{Fd}$ and $\left.\Delta \mathrm{Fq}\right)$. In contrast to the monomers $\Delta \mathrm{Fm} / \mathrm{Fm}\left(\mathrm{IC}_{50}>100 \mu \mathrm{M}\right)$, the dimers showed potent $\left\{\mathrm{IC}_{50}:(\Delta \mathrm{Fm})_{2} 2.4 \mu \mathrm{M}, \Delta \mathrm{Fd} 1.39 \mu \mathrm{M}\right.$, D-Lys- $\Delta \mathrm{Fd} 1.8 \mu \mathrm{M}$, Fd $1.5 \mu \mathrm{M}\}$ dose dependent anti-plasmodial action against the growth of CQ-sensitive, blood stage parasite (P. falciparum 3D7) in culture. Interestingly the $\mathrm{K}-\mathrm{K}_{2}$ branched tetrameric dendrimer $\Delta \mathrm{Fq}$ with $\mathrm{IC}_{50} 0.25 \mu \mathrm{M}$ turned out to be the most potent anti-plasmodial in the present series. The progressive increment in antiplasmodial potency with valency of the peptides suggests an oligomeric state of the peptide is associated with potency. The haemolysis-based selectivity indices for the potent peptides were $>35(\Delta \mathrm{Fd}),>20(\Delta \mathrm{Fm})_{2}$, $>27$ (D-Lys- $\Delta \mathrm{Fd}),>33(\mathrm{Fd})$ and $10(\Delta \mathrm{Fq})$. The favourable index of $>35$ for $\Delta \mathrm{Fd}$ became the reason to study this

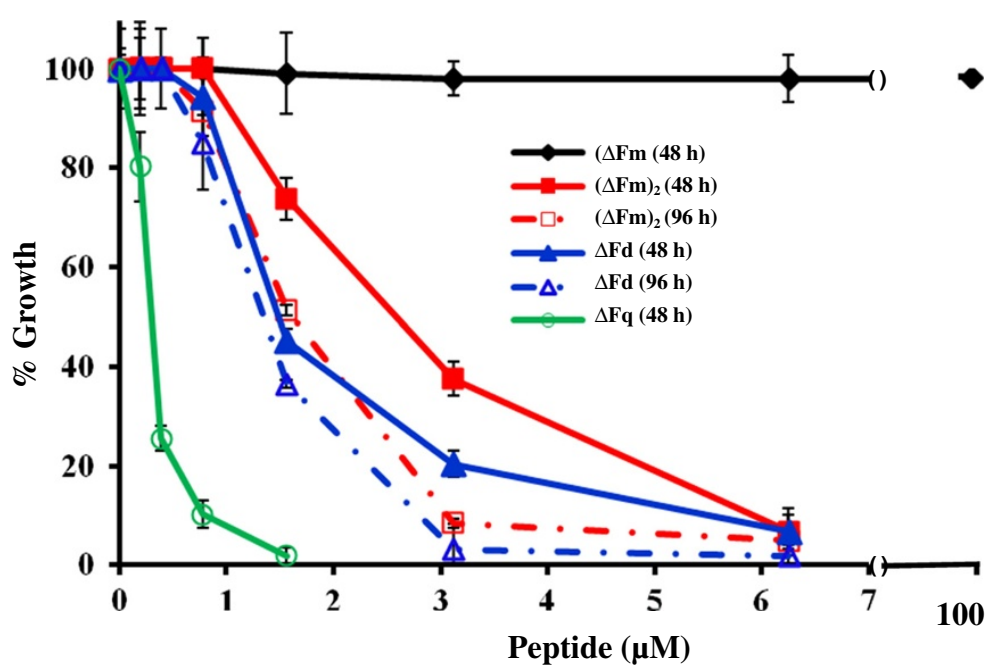

Figure 1 Multivalent cationic, amphipathic helical peptides are potent inhibitors of the growth of malaria parasite in culture. Dose-dependent effects of $\Delta \mathrm{Fm}$ (monomer), $\left[(\Delta \mathrm{Fm})_{2}\right.$ and $\left.\Delta \mathrm{Fd}\right]$ (dimers) and $\Delta \mathrm{Fq}$ (quadrumer) on the growth of ring-stage synchronized Plasmodium falciparum (3D7) culture of malaria parasite. The anti-plasmodial potency increases in going from monomer $\Delta \mathrm{Fm}$, to dimers $[\Delta \mathrm{Fd}$, and $(\Delta \mathrm{Fm})_{2}$ ] and the quadrumer $\Delta \mathrm{Fq}$. The marginal difference in the comparative growth inhibition profiles of the two dimers at $48 \mathrm{hr} v \mathbf{v s} \mathrm{hr}$ suggests that there is predominantly early death. Each data point represents the mean+/- SD of three replicates. 


\section{A Ring Stage synchronized culture after 48 ha}

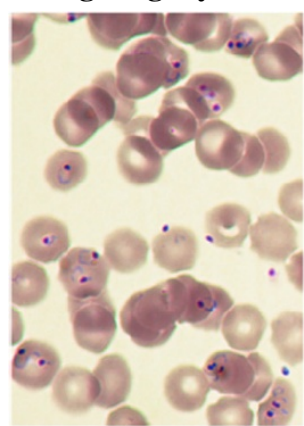

Untreated

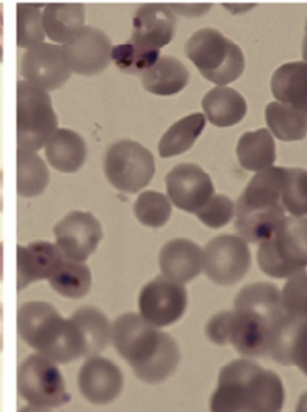

$\Delta \mathrm{Fd} 1.56 \mu \mathrm{M}\left(\mathrm{IC}_{50}\right)$

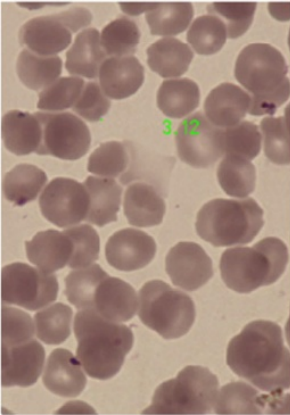

$3.12 \mu \mathrm{M}\left(\mathrm{IC}_{80}\right)$

B Trophozoite stage synchronized culture after $24 \mathrm{~h}$

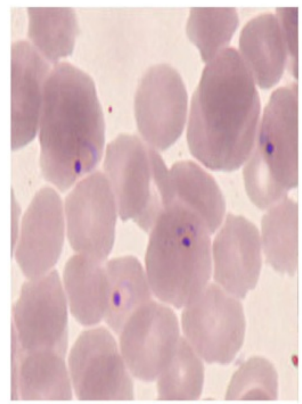

Untreated

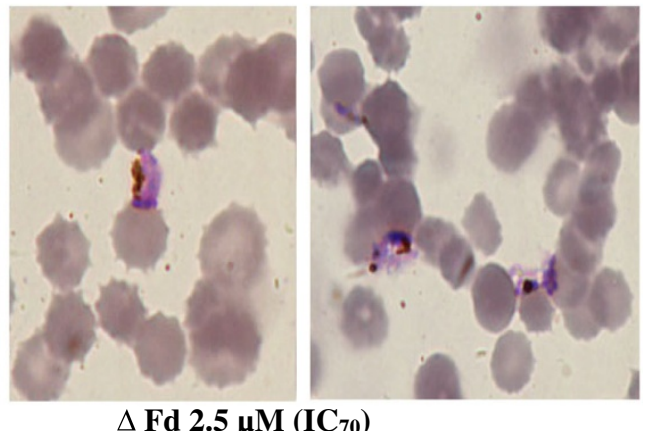

$\Delta \mathrm{Fd} 2.5 \mu \mathrm{M}\left(\mathrm{IC}_{70}\right)$

C Schizont stage Synchronized culture after 6- $12 \mathrm{~h}$.

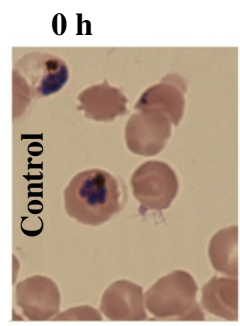

\begin{abstract}
6h
\end{abstract}
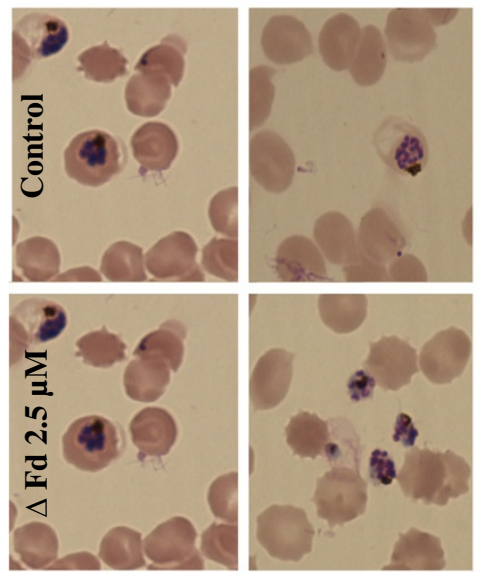

$9 \mathrm{~h}$
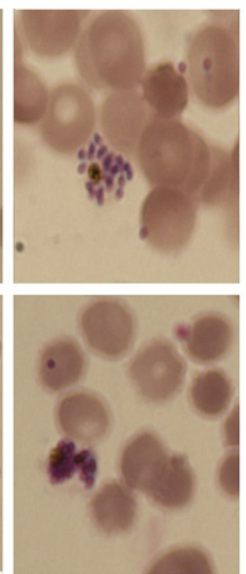

$12 \mathrm{~h}$
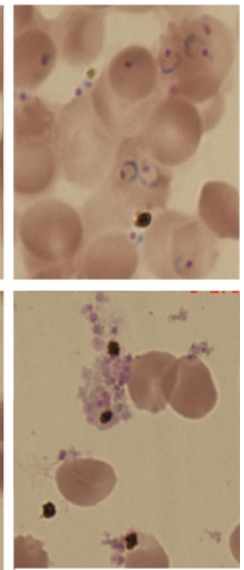

Figure 2 Microscopy of anti-plasmodial action of $\Delta \mathrm{Fd}$ on Plasmodium falciparum 3D7. (A) Untreated or $\Delta \mathrm{Fd}$-treated, ring-stage synchronized cultures (parasitaemia 1\%) were observed after $48 \mathrm{hr}$. Untreated culture shows high ring-stage parasitaemia, $\Delta \mathrm{Fd} I \mathrm{C}_{50}$ and IC 80 treated cultures show low trophozoite-stage and low ring-stage arrested parasitaemia respectively, (B) Untreated or $\Delta$ Fd-treated trophozoite-stage synchronized cultures were observed after $24 \mathrm{hr}$. Untreated culture shows intracellular rings while the $\Delta$ Fd-treated culture shows anomalously egressed trophozoites. Note the selectivity in action on parasitized cells with no effect on uninfected cells. (C) Untreated or $\Delta$ Fd-treated schizont stage synchronized cultures were observed at 6-12 hr. While schizonts with the characteristic rosette arrangement of merozoites are intracellular at $6 \mathrm{hr}$ in untreated culture, they have (a) prematurely egressed and (b) lost the rosette arrangement of merozoites in the peptide treated culture (For zoom of the images, see additional file 10, panel A). At $12 \mathrm{hr}$ while the merozoites in control have invaded fresh red cells to form rings, the merozoites of peptide treated cultures have failed to invade and form rings (For quantitative account of decrease in invasion events, see additional file 10, panel C). 
peptide in greater detail. Further, $(\Delta \mathrm{Fm})_{2}$ was studied since it was interesting to compare a linear dimer with a branched dimer. The $\mathrm{K}-\mathrm{K}_{2}$ dendrimeric quadrumer was not studied in detail due to its poor haemolytic index. Several control peptides (Table 1) including sequences corresponding to prochitinase, E30, and bovine insulin showed no inhibition up to a concentration of $40 \mu \mathrm{M}$. Interestingly, both $(\Delta \mathrm{Fm})_{2}$ and $\Delta \mathrm{Fd}$ retained their anti-plasmodial potencies also against the CQ-resistant $\mathrm{Dd} 2$ strain resulting in resistance index values of $\sim 1$ (Table 1). The more potent, branched dimer $\Delta \mathrm{Fd}$ showed $\mathrm{IC}_{50}$ value of $1.5 \mu \mathrm{M}$ against the highly CQ-resistant INDO strain of $P$. falciparum. These results showed that dimerization potentiates antiplasmodial activity by more than 50 -fold over the corresponding monomer. The small but significant difference (student's $T$ test p: 0.013 ) between the potencies of the linear $\left[\mathrm{IC}_{50}:(\Delta \mathrm{Fm})_{2} \quad 2.4 \mu \mathrm{M}\right]$ and branched $\left(\mathrm{IC}_{50}: \Delta \mathrm{Fd} 1.39 \mu \mathrm{M}\right)$ dimers suggests that the mode of dimerization may also play a subtle role in modulation of potency. When examined for comparative potency in $48 \mathrm{hr}$ (one cycle) vs $96 \mathrm{hr}$ (two cycles) assays, only marginal increments in potency [1.5 fold $(\Delta \mathrm{Fm})_{2}$, and 1.1 fold $\left.\Delta \mathrm{Fd}\right]$ were observed at $96 \mathrm{hr}$ (Figure 1).

\section{Ring vs trophozoite: selectivity in the action of $\Delta \mathrm{Fd}$}

In order to find whether there was ring $v s$ trophozoite selectivity in the action of $\Delta \mathrm{Fd}$, microscopic evaluation of its action was studied against parasitized red cells synchronized at ring (Figure 2A) and trophozoite (Figure 2B) stages respectively. When the ring stage parasite culture was treated with $\mathrm{IC}_{50}$ dose of $\Delta \mathrm{Fd}$, it was observed (Figure 2A) that, after $48 \mathrm{hr}$ of culture, the rings had progressed only up to the trophozoite stage suggesting biochemical arrest and the resulting interception of the progression to the schizont stage. Further at $\mathrm{IC}_{80}$, it was observed that the rings did not mature even to the trophozoite stage and the arrest of the parasite cycle was at the ring stage. Since $\Delta \mathrm{Fd}$ at its $\mathrm{IC}_{50}$ caused arrest at trophozoite stage (Figure $2 \mathrm{~A}$ ), the effect of $\Delta \mathrm{Fd}$ at its $\mathrm{IC}_{70}(2.5 \mu \mathrm{M})$ was tested on cultures synchronized at trophozoite stage. It was interesting to see (Figure $2 \mathrm{~B}$ ) that the peptide caused anomalous egress of trophozoites. Even as $95 \%$ of trophozoites were found to be extracellular (Additional file 8); this phenomenon was not a consequence of non-specific haemolysis since uninfected red cells were not affected (Figure 2B). Thus it appears that at $\sim \mathrm{IC}_{80}$ rings are metabolically arrested and the RBCs harbouring them are not lysed while such doses cause selective lysis of parasitized RBCs that harbour trophozoites. The observation of MSP3 staining in 40\% of the anomalously egressed trophozoites (Additional file 9) is worth noting.

\section{$\Delta \mathrm{Fd}$ is fairly non toxic to mammalian HeLa cells}

Toxicity of $\Delta \mathrm{Fd}$ to mammalian cells was examined by MTT assay. HeLa cells incubated with varying concentrations $(2.5-25 \mu \mathrm{M})$ of $\Delta \mathrm{Fd}$ (Figure 3 ) did not show any toxicity. This suggests that the therapeutic index $\left(\mathrm{TC}_{50}\right.$ Mammalian cells/IC 50 P.falciparum) of this peptide (>16) is promising.

\section{$\Delta \mathrm{Fd}$ causes premature egress of undifferentiated Schizonts}

While it is unnatural for trophozoites to egress, the egress of schizonts is a natural process that leads to increased parasitemia. It was therefore interesting to find the effect of $\Delta \mathrm{Fd}$ on egress of schizonts. As shown (Figure $2 \mathrm{C}$ ), the peptide treated cultures showed premature egress at $6 \mathrm{~h}$ at a time when the schizonts in the control culture were intracellular. A close look at the schizonts of the control and the peptide treated cultures (see Additional file 10, panel A) revealed that (a) The characteristic symmetric rosette arrangement of merozoites seen in control at $6 \mathrm{hr}$ and $9 \mathrm{hr}$ is absent in the prematurely egressed schizonts of the peptide treated culture and (b) the well differentiated merozoites of the control are invasion competent which enables them to form new rings while the merozoites of the peptide-treated culture are invasion disabled resulting in no new infections of red blood cells. Interestingly merozoites from both the control and peptide treated schizonts were found to be MSP3+ (Additional file 9).

\section{Selective haemolytic effect of $\Delta \mathrm{Fd}$}

The anomalous egress of trophozoites via haemolysis motivated an examination of the selectivity in the action of $\triangle \mathrm{Fd}$ against parasitized (PRBC) vs uninfected red cells (URBC) over a range of peptide concentrations. As shown (Figure 4A), while the URBCs showed considerable resistance to lysis, the PRBCs showed increasing lysis both with increasing concentration of peptide and also with increasing parasitaemia. It may be noted that the observed lysis is proportional to the percentage of

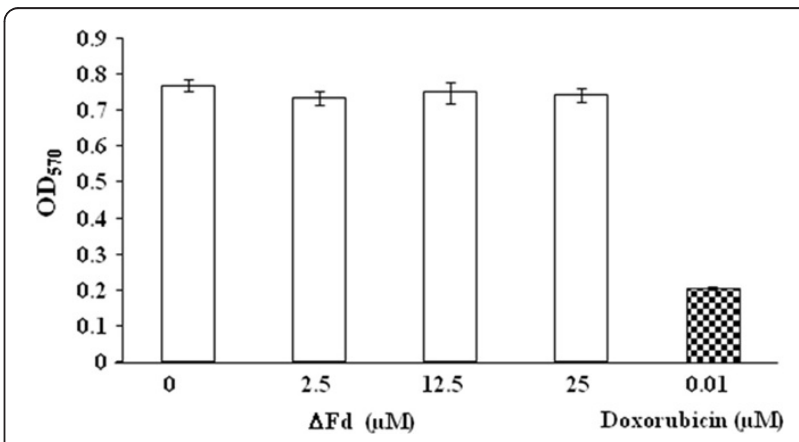

Figure 3 Histogram showing results of MTT assay measuring viability of HeLa cells incubated with $\Delta \mathrm{Fd}$ at different concentrations. Data shows mean and standard deviation of three independent observations. 

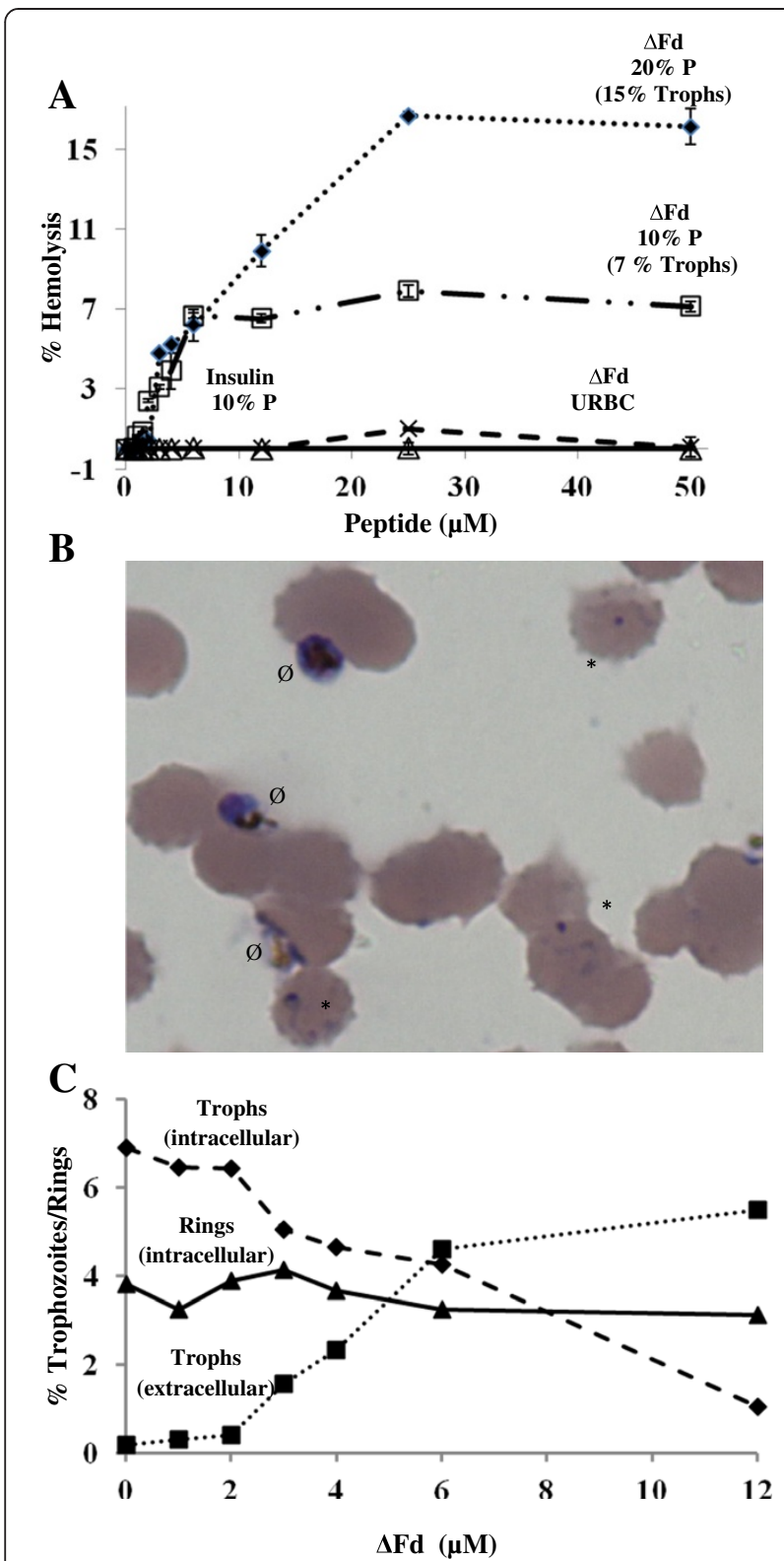

Figure $4 \Delta \mathrm{Fd}$ causes selective haemolysis of parasitized red cells leading to anomalous egress of trophozoites. (A) Samples of mixed stage parasite culture at different parasitaemia (P) (\% figures on respective curves) were incubated ( $3 \mathrm{hr}$ ) with the indicated concentrations of peptide and percentage haemolysis estimated by $\mathrm{A}_{415}$. Control peptide (insulin) with infected red cells (10\% trophozoite-stage parasitaemia, solid line); $\triangle \mathrm{Fd}$ with URBC (dashed line); $\Delta \mathrm{Fd}$ with $10 \%$ parasitaemia (rings $3 \%$, trophozoites $7 \%$, dashed dotted line); and $\Delta \mathrm{Fd}$ with $20 \%$ parasitaemia (rings $5 \%$, trophozoites 15\%, dotted line). Two other control peptides (prochitinase and E30) behaved like insulin (data not shown). (B) Shows microscopic analysis of the selective sensitivity of trophozoites $\left(\varnothing\right.$, anomalously egressed) vs rings ${ }^{*}$, intracellular) at $12 \mu \mathrm{M} \Delta \mathrm{Fd}$, (C) shows dose-dependent selective effect of $\Delta \mathrm{Fd}$ on anomalous egress of trophozoites but not rings, monitored microscopically after incubation (3 hr). Data shown were obtained after counting 2,000 erythrocytes. trophozoites in the cultures tested. Thus in the two mixed cultures shown in Figure 4A, the percentage haemolysis values of $7 \%$ and $16 \%$ correspond to percentage trophozoite populations of $\sim 7 \%$ and $15 \%$, respectively. Further microscopic evaluation of mixed parasite cultures treated with $\Delta \mathrm{Fd}(12 \mu \mathrm{M})$ revealed (Figure $4 \mathrm{~B}$ ) that only the trophozoites and not the rings were observed to be extracellular. In order to find if the observed lysis of infected cells was specific to $\Delta \mathrm{Fd}$ or would any peptide in general cause similar lysis, three control peptides (insulin, E30 and prochitinase) (Figure 4A) were tested and found not to show any haemolysis up to a concentration of $40 \mu \mathrm{M}$. Microscopic examination of $\sim 2,000$ cells from infected red cell cultures revealed a peptide concentration dependent inverse relation between intracellular vs extracellular trophozoites (Figure 4C). Also evident from this figure is the stability of ring-infected cells up to $12 \mu \mathrm{M}$ of $\Delta \mathrm{Fd}$.

\section{Anomalously egressed trophozoites are not surrounded by host cell membrane}

Immunostaining with band 3 antibody was done in order to find if the trophozoites egressed in response to $\Delta \mathrm{Fd}$ were free or packaged in host cell membrane. As shown in Figure 5, while the untreated culture showed the DAPI

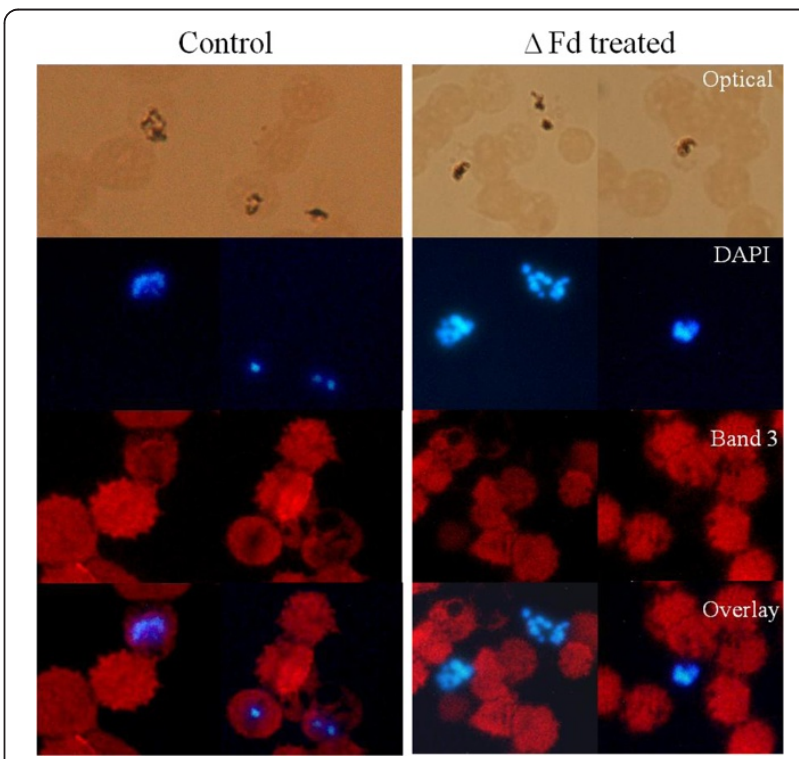

Figure $5 \Delta \mathrm{Fd}$-mediated parasite egressed from red blood cells are not coated with host cell membrane. Bright field optical images (top panel) show haemozoin crystals that are intracellular in control and appear to be extracellular in $\Delta \mathrm{Fd}(12.5 \mu \mathrm{M})$-treated sample. Panel 2 shows DAPI stained nuclei of the malaria parasite. Panel 3 (immunostaining with band 3 antibody) indicates that band 3 (red) was seen in all cells. Panel 4 (overlay of DAPI and band 3) indicates that the parasites (staining blue) in control panel are intracellular and flanked by band 3 stain. But the $\Delta \mathrm{Fd}$-treated parasites, which egressed anomalously, are extracellular and not flanked by band 3 . 
stained parasites to be intracellular and flanked by band 3 staining (red), the egressed extracellular trophozoites in the $\Delta$ Fd-treated culture $(12.5 \mu \mathrm{M})$ had no band 3 staining around them. This observation suggests that egress does not involve host cell membrane and is likely to be mediated via lysis of the host cell.

A

FITC- $\Delta$ Fd

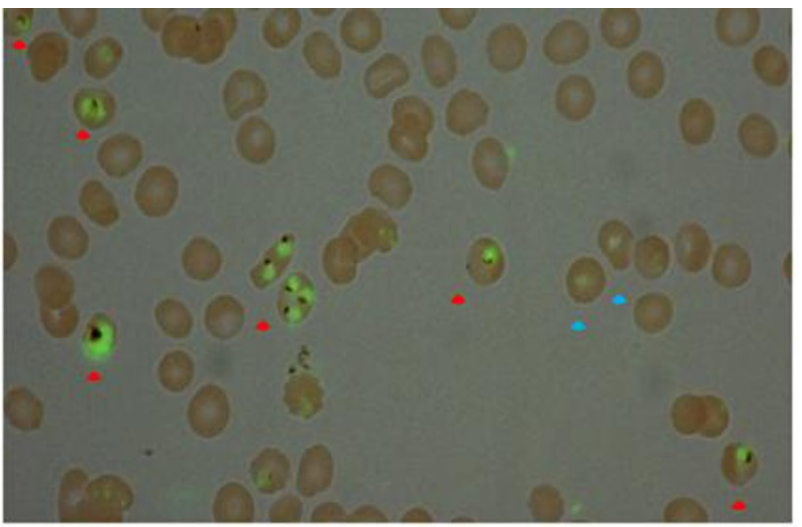

$\mathbf{B}$

FITC- $\Delta$ Fd

FITC- $(\Delta \mathrm{Fm})_{2}$

FITC- Insulin
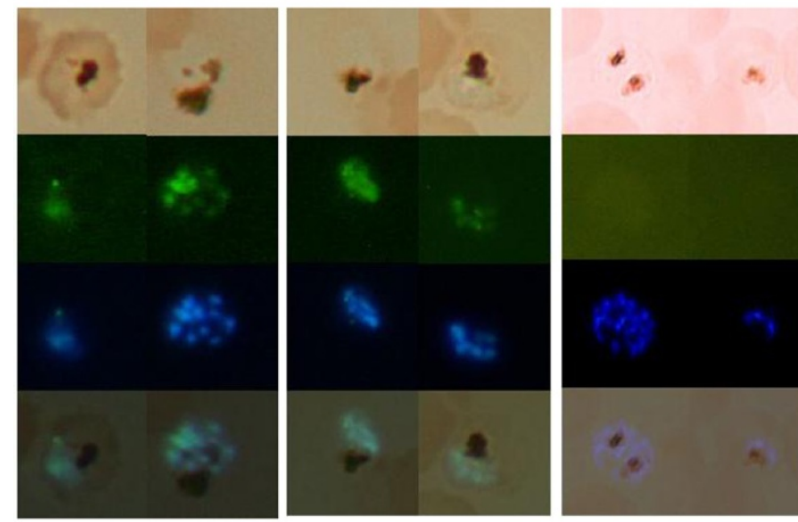

Bright
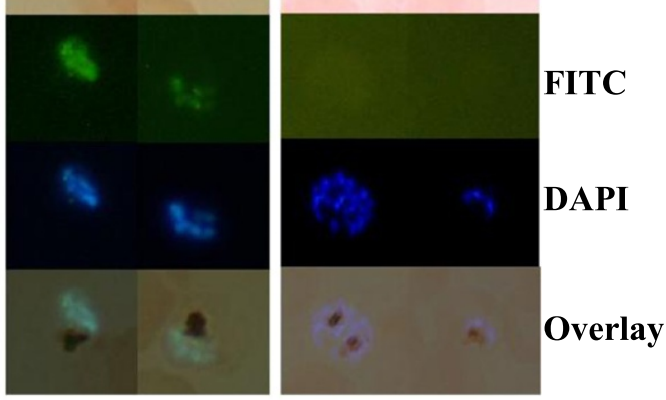

URBC URBC

PRBC

PRBC

PRBC

$4^{\circ} \mathrm{C}, 30^{\prime} \quad 2^{\circ} \mathrm{C}, 30^{\prime}$

$4^{\circ} \mathrm{C}, \mathbf{3 0}^{\prime}$

$25^{\circ} \mathrm{C}, 10$

$25^{\circ} \mathrm{C}, 30^{\prime}$

C
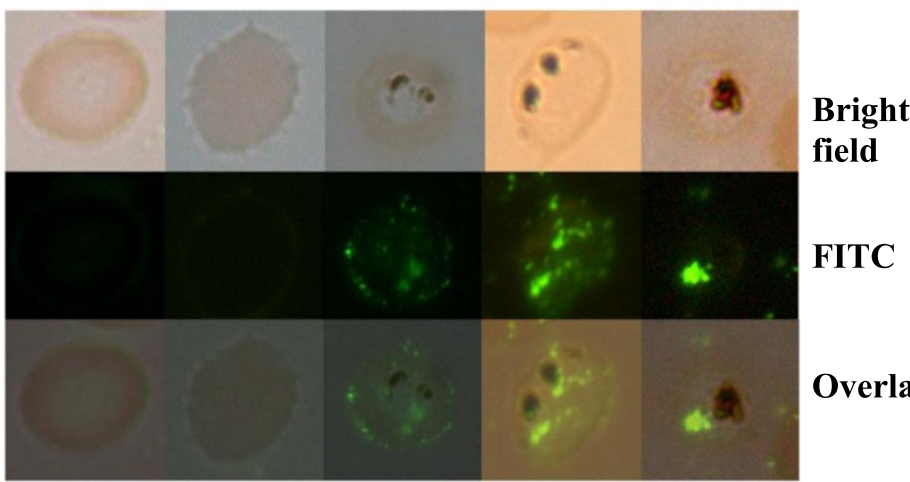

field

FITC

\section{Overlay}

Figure 6 Cellular localization of FITC-labelled peptides in Plasmodium falciparum-infected red blood cells. (A) FITC- $\Delta$ Fd $(3 \mu \mathrm{M})$ was incubated with parasitized culture $\left(30 \mathrm{~min}, 37^{\circ} \mathrm{C}\right)$. Fluorescence image overlaid on optical image shows that FITC- $\Delta$ Fd exhibits selective entry into parasitized RBCs. Arrow heads.red (trophozoites showing haemozoin), blue (likely to be ring stages with low fluorescence). (B) FITC- $\Delta$ Fd and FITC$(\triangle \mathrm{Fm})_{2}$ but not FITC-insulin are internalized by PRBC. The overlay of FITC fluorescence (green) with DAPI (blue) suggests that these two peptides bind to DNA of the parasite. (C)Transport of FITC- $\Delta F d(4 \mu M)$ from RBC surface to parasite: $\Delta$ Fd has selective affinity for infected RBC (PRBC) surface. The slow entry of FITC- $\Delta \mathrm{Fd}$ into PRBC at $4^{\circ} \mathrm{C}$ becomes fast at $25^{\circ} \mathrm{C}$. 


\section{Dimers $\Delta \mathrm{Fd}$ and $(\Delta \mathrm{Fm})_{2}$ show selective penetration into Plasmodium-infected RBCs}

To gain a better understanding of the anti-plasmodial action of the two dimeric peptides, localization of peptides was studied using fluorophore-labelled peptides. Fluorescence microscopy with FITC-labelled $\Delta \mathrm{Fd}$ showed that this peptide was selective in targeting the parasite inside the infected RBC (Figure 6A). Colocalization of FITC florescence (green) with DAPI florescence (blue) (Figure 6B) indicated that the two peptides bind to the DNA of the malaria parasite. In order to check whether entry of the two dimers was specific or would any other peptide also enter parasitized cells, FITC-labelled insulin was examined for uptake by the parasitized cells. Fluorescence microscopy revealed that there was no accumulation of FITC-insulin in parasitized cells suggesting specificity in uptake and anti-plasmodial action of the two dimeric peptides. Since no fluorescence was observed on the red cell surface even as there was intense fluorescence intracellularly, it was surmised that the uptake of the peptide may be faster than the time (30 min) given for the experiment. In order to capture early events in transfer of the peptide from the RBC surface to the parasite, a comparative uptake study at $4^{\circ} \mathrm{C}$ $v s$ at $25^{\circ} \mathrm{C}$ was performed. As shown (Figure 6C), while the URBC showed no staining, the PRBC at $4^{\circ} \mathrm{C}$ showed predominantly surface staining with a modicum of intracellular staining. However PRBC at $25^{\circ} \mathrm{C}$ showed a transition from surface to intracellular staining at $10 \mathrm{~min}$ which became completely intracellular at $30 \mathrm{~min}$. Thus it appears that parasite-infected red blood cells are well geared for rapid uptake of this peptide.

\section{Uptake kinetics of $\Delta \mathrm{Fd}$}

In order to assess the kinetics of uptake of the fluorescently tagged peptide into the infected red cells, a timedependent analysis of the phenomenon was studied by FACS. Monitoring the uptake in ring-synchronized cultures (Figure 7) revealed a low uptake (1.97\%) at the first minute rising to $\sim 3 \%$ at $20 \mathrm{~min}$. In contrast to rings, the analogous peptide uptake by trophozoites was found to be fast at the very first minute (7.6\%) with further substantial rise to $22 \%$ at $20 \mathrm{~min}$.

\section{Discussion}

The success of antibiotics is based upon the characteristic molecular targets that distinguish the prokaryotic bacteria from the nucleated eukaryotic cells [32,33]. Cationic, amphipathic helical, antibiotic peptides also seem to gain specificity by exploiting the fact that bacteria have a preponderance of anionic lipids, such as phosphatidylglycerol and bis(phosphatidyl)glycerol (cardiolipin), conferring a negative charge on their surface. In contrast, their eukaryotic counterparts have a high density of zwitterionic lipids such as phosphatidylcholine and phosphatidylethanolamine, enabling their surfaces to be largely neutral [34,35]. A well-studied and yet curious feature of the human red blood cell is the transition from FITC-Annexin negative to FITC-Annexin positive status upon infection with the malaria parasite [14]. It is

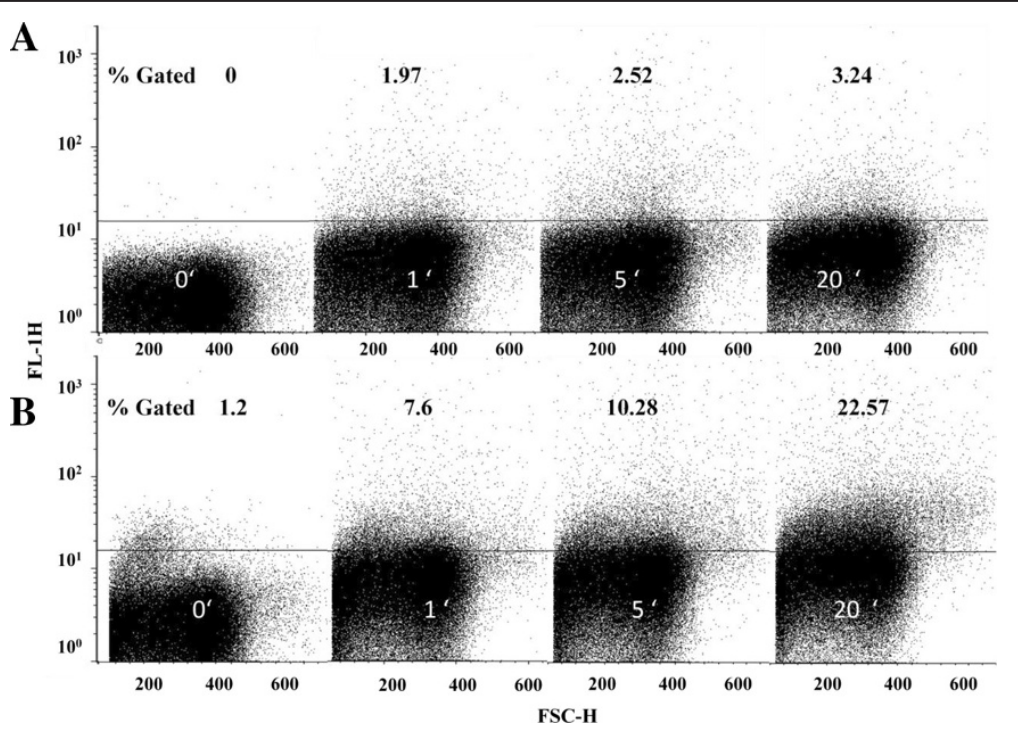

Figure 7 Kinetics of $\Delta \mathrm{Fd}$ entry into parasitized red blood cells (synchronized rings ( $7 \%$ parasitaemia) and synchronized trophozoites ( 20\% parasitaemia). Uptake of fluorescently tagged FITC- $\Delta \mathrm{Fd}(2.5 \mu \mathrm{M})$ was monitored by flow cytometry at $25^{\circ} \mathrm{C}$. Panels $\mathrm{A}$ and $\mathrm{B}$ depict the peptide uptake profiles obtained with rings and trophozoites, respectively. Zero minute profiles correspond to samples not treated with peptide. Figures against percentage gated indicate the number of cells stained above the threshold line. Note (a) the fast uptake and progressive increase in the number of fluorescent signals with time, and (b) faster uptake by trophozoites compared to ring-stage parasitized cells. 
well known that this phenomenon is caused by the translocation of the anionic phosphatidylserine from the inner to the outer leaflet of the lipid bilayer. Thus infection with Plasmodium confers an anionic character to the red blood cell giving it a shade of semblance to a bacterial membrane. Focusing on the altered membrane asymmetry seen in the infected red cell, the interesting anti-plasmodial properties of several de novo-designed, cationic, amphipathic, helical, bonafide membrane-active anti-bacterial peptides have been examined in the present studies.

The first observation of the comparative anti-plasmodial potencies of two monomeric $(\Delta \mathrm{Fm}, \mathrm{Fm})$ and four dimeric peptides $\left\{\Delta \mathrm{Fd}, \mathrm{Fd}, \mathrm{D}\right.$-Lys $\left.-\Delta \mathrm{Fd},(\Delta \mathrm{Fm})_{2}\right\}$ (Table 1$)$ indicated that the dimers $\left(\mathrm{IC}_{50} 1.39-2.4 \mu \mathrm{M}\right)$ were about two orders of magnitude more potent than the monomers $\left(\mathrm{IC}_{50}>100 \mu \mathrm{M}\right)$. Among the dimeric peptides $\left\{\Delta \mathrm{Fd}: \mathrm{IC}_{50} 1.39 \mu \mathrm{M}, \mathrm{D}\right.$-Lys- $\Delta \mathrm{Fd}: \mathrm{IC}_{50} 1.8 \mu \mathrm{M}$, $\left.(\Delta \mathrm{Fm})_{2}: \mathrm{IC}_{50} 2.4 \mu \mathrm{M}, \mathrm{Fd}: \mathrm{IC}_{50} 1.5 \mu \mathrm{M}\right\}$, the lysinebranched $\Delta \mathrm{Fd}$ was chosen for detailed mechanistic studies since it had favourable features of anti-plasmodial potency and selectivity index $(>35)$. Interestingly, in going from this bivalent-branched dimer $\Delta \mathrm{Fd}$ to the tetravalent $\mathrm{K}-\mathrm{K}_{2}$-branched quadrumer $\Delta \mathrm{Fq}\left(\mathrm{IC}_{50}: 0.25 \mu \mathrm{M}\right)$, a further six-fold potentiation was observed. However, as shown in Table 1 , this potentiation was associated with a decline in selectivity index from $>35(\Delta \mathrm{Fd})$ to $10(\Delta \mathrm{Fq})$. Nevertheless, the trend of increasing anti-plasmodial potency with increasing valency (monomer to dimer to quadrumer) of the peptide suggests that oligomerization on cell surfaces may play an important role in the antiplasmodial action of these cationic, amphipathic peptides. It is important to note that crystal structures of several $\Delta \mathrm{F}$-containing peptides have revealed the propensity of this planar aromatic residue to engage in long-range, multicentred interactions (N-H...O, C-H...O, C-H...л, and $\mathrm{N}-\mathrm{H} \ldots \pi)$ that can stabilize oligomeric states like the $\Delta \mathrm{F}$ zipper [36] in the absence of linker, or the helical hairpins in the presence of appropriate linker $[37,38]$. The coming together of optimal values of anti-plasmodial potency and selectivity indices (haemolytic selectivity index $>35$ and mammalian cell cytotoxicity index $>16$ ) in the lysinebranched dimeric $\Delta \mathrm{Fd}$ became the motivation to unravel mechanistic details of the anti-plasmodial action of this peptide. $(\Delta \mathrm{Fm})_{2}$, the corresponding linear dimer, was also studied in some experiments to explore if the mode of dimerization may influence the anti-plasmodial actions of these two dimeric peptides.

The essentiality of apicoplast, an organelle of cyanobacterial origin in the malaria parasite, is well known to make the parasite vulnerable to antibiotics,such as tetracycline, clindamycin and thiostrepton $[39,40]$, which are known to cause delayed death in malaria parasite. This phenomenon, caused by targeting of the apicoplast or the mitochondrion, is characterized by a significantly lower $\mathrm{IC}_{50}$ post second cycle (at $96 \mathrm{hr}$ ) vs the first cycle (at $48 \mathrm{hr}$ ) [41]. In order to find if the anti-plasmodial peptides under study may be targeting organelles such as the apicoplast of the malaria parasite, comparative anti-plasmodial potencies against $P$. falciparum 3D7 were determined at both $48 \mathrm{hr}$ and $96 \mathrm{hr}$. Since the data (Figure 1) did not show a significant reduction of $\mathrm{IC}_{50}$ at $96 \mathrm{hr}$, the possibility that $\Delta \mathrm{Fd}$ and $(\Delta \mathrm{Fm})_{2}$ may cause early death by influencing several other targets besides the apicoplast and the mitochondria cannot be ruled out.

In trying to gain a better understanding of the probable mechanisms that confer the malaria parasite growth inhibitory properties on the dimeric peptide $\Delta \mathrm{Fd}$, the peptide-treated samples were examined by microscopy. As shown (Figure 2A), in comparison to the untreated control (high ring-stage parasitaemia), while the $\mathrm{IC}_{50}$-treated ring stage synchronized culture was found to have the initial low parasitaemia (1\%) and growth arrest at trophozoite stage, the $\mathrm{IC}_{80}$ treated sample was found to have the intial parasitaemia (1\%) with the few parasitized cells showing arrested, probably dead pyknotic ring forms. Interestingly, the microscopic examination of the $\Delta$ Fd-treated, trophozoite-enriched culture (Figure 2B) showed the presence of extra erythrocytic Giemsa-positive trophozoites alongside uninfected red blood cells. Indeed manual counting of a large number of fields (Additional file 8) indicated that over $95 \%$ of the trophozoites were in fact extracellular. The presence of extracellular trophozoites in the midst of intact uninfected red blood cells was suggestive of the selective haemolytic action of $\Delta \mathrm{Fd}$ on parasitized cells causing anomalous release of trophozoites following 24-hr incubation.

The transition of ring stage to trophozoite stage in presence of $\Delta \mathrm{Fd}$ at its $\mathrm{IC}_{50}$, indicates that while this low dose is sufficient to arrest trophozoites, it is clearly not sufficient to halt the ring from moving to the trophozoite stage (Figure 2A). This heightened sensitivity of trophozoite-stage cultures over ring-stage cultures may be related to the enormous red cell reorganizational changes associated with a fast feeding, actively metabolizing and replicating life style of trophozoite in comparison with the more sedentary ring stage. The selective lysis of trophozoite-bearing cells (Figure 4B) also suggests that such remodelling of the trophozoite harbouring red cell membrane [42] may be rendering it more vulnerable to the action of membrane active peptides like the $\Delta \mathrm{Fd}$. The greater vulnerability of trophozoite bearing over ring-bearing red cells is evident also from the fact that peptide-mediated haemolysis is directly proportional to the percentage trophozoites in mixed stage culture samples (Figure 4A).

Trophozoite egress, induced by the peptide, is not natural to the life cycle of the malaria parasite. Hence, it 
was important to find if host cell membranes-may be involved in the process. To address this issue, the peptide-treated sample was exposed to immunostaining with band 3 antibody. As shown (Figure 5), the egressed trophozoites were not flanked by band 3 staining suggesting that the process is more likely to be caused by lysis of the infected host cell. A closer examination of the phenomenon of $\Delta \mathrm{Fd}$-mediated anomalous egress of trophozoites revealed that in trophozoite-ring mixed culture exposed to FITC- $\Delta \mathrm{Fd}$ at low concentrations $(2 \mu \mathrm{M})$ and short time (30 min) (Figure 5A), the peptide seems to enter and attack the parasite from within without causing immediate lysis of the infected red cell. However when trophozoite-stage culture was exposed to $\Delta \mathrm{Fd}$ for longer times $(24 \mathrm{hr})$, at similar low concentrations $(2 \mu \mathrm{M})$, this peptide seemed to cause selective lysis of parasitized cells leading to anomalous egress of trophozoites (Figure 2B). Further, at higher concentrations $(12.0 \mu \mathrm{M})$ this peptide caused selective lysis of red cells harbouring trophozoites within $3 \mathrm{hr}$ (Figure 4B).

Unlike trophozoites, schizonts have an intrinsic program of egress that causes the release of numerous merozoites leading to infection of fresh red cells causing amplification of infection and increasing the severity of disease. Hence it was interesting to find if $\Delta \mathrm{Fd}$ may perturb the programmed process of egress in schizonts. As shown (Figure 2C and Additional file 10), this peptide caused premature egress of schizonts. As a consequence, the egressed schizonts which showed lumps of amplified DNA did not exhibit the characteristic symmetrically organized rosette appearance of merozoites seen in the untreated control schizont. Further the merozoites from the peptide treated culture showed a significantly low invasion efficiency in comparison to the control merozoites (Additional file 10). Figure 8 summarizes the versatility of $\Delta \mathrm{Fd}$ to target each stage of the life cycle of $P$. falciparum in characteristic and decisive ways with good selectivity.

Malaria parasites go to extraordinary means to modify RBC membrane, which separates them from the external world. These modifications include a marked increase in erythrocyte membrane fluidity [43-46], alterations in host cell lipid fatty acid composition [47,48] and phospholipid-transbilayer distribution [49], enhancement of the rate of lipid transbilayer movement [50,51] and increased permeability through newly formed pores on the erythrocyte membranes [52,53]. As a part of these major re-organizational events, the malaria-infected red cell is well known to exhibit a translocation of the anionic phosphatidylserine from the inner leaflet to the outer leaflet of the bi-layer [13,54]. This more negative cell surface may provide the force for the fast and specific uptake of cationic peptides by the malaria-infected red cell. Previous studies have indicated that high levels

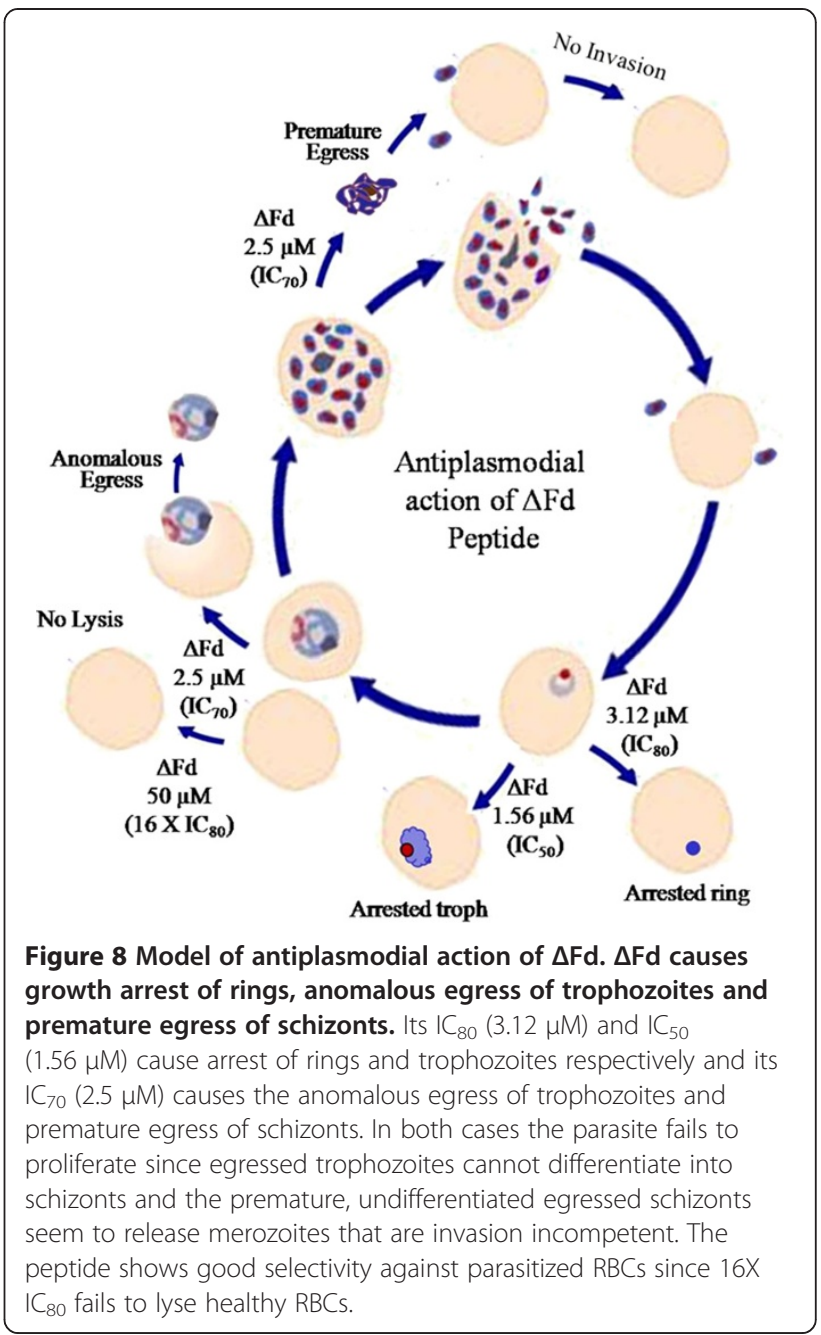

of cellular uptake can be achieved through the inclusion of cationic residues into arginine-based peptide oligomers [55]. The positive molecular charge facilitates charge-driven uptake through the plasma membrane, which exhibits a potential gradient that can electrophorese cationic species from the extracellular space into the cell [56,57]. Interestingly, a recent study has demonstrated that membrane asymmetry can be altered and maintained in the altered state by externally added polyL-lysine [58]. The combined microscopic (Figure 6) and FACS analysis (Figure 7) suggests that $\triangle F d$ enters the infected cells and stains rings and trophozoites within a few minutes. Thus it is quite likely that $\Delta \mathrm{Fd}$ and $(\Delta \mathrm{Fm})_{2}$, the two cationic dimeric peptides studied here, in close resemblance to poly-L-lysine, may first home on those infected red blood cells that show slightly more anionic character as a result of alterations in membrane asymmetry and binding of these cationic peptides could further enhance and maintain this anionic character facilitating the stronger binding and faster internalization of peptides into the infected cells. 
The ability of $\Delta \mathrm{Fd}$ to cross the host red cell membrane, the parasitophorous vacuole membrane, the parasite plasma membrane and also the parasite nuclear membrane to reach the nucleus of the parasite (Figure 6B), indicates its resemblance to cell-penetrating peptides which are known to have a lipophilic-cationic character. Even as the peptide was apparently targeting the DNA of the parasite, the absence of FITC- $\Delta \mathrm{Fd}$ on the host red cell membrane or all the subsequent membranes mentioned above was puzzling. It was surmised that these localizations may have been missed due to the rapidity of the process of peptide uptake. In order to capture some stages preceding the intranuclear entry of the peptide, the peptide-staining experiment was performed as a function of both time and temperature. As shown (Figure $6 \mathrm{C})$, the images captured at $4^{\circ} \mathrm{C}(30 \mathrm{~min})$ indeed showed predominant staining on the host cell surface. In contrast, the images corresponding to $25^{\circ} \mathrm{C}$ $(10 \mathrm{~min})$ and $25^{\circ} \mathrm{C}(30 \mathrm{~min})$ showed progressively greater staining of the intracellular parasite nuclear material. These results suggest that this peptide crosses several membranes of the infected red cells before entering the nucleus.

The most probable reasons for the significantly enhanced potency of the dimers $\Delta \mathrm{Fd} / \mathrm{Fd}$ over the monomers $\Delta \mathrm{Fm} / \mathrm{Fm}$ include increased membrane binding and permeabilization, enhanced binding affinity for DNA and proteins and enhanced biochemical stability against degradation by proteases. These properties originating from increased avidity and affinity of interactions unique to dimeric peptides and absent in monomeric peptides have been described previously [25]. In studies on the antibiotic action of these peptides it has previously been observed that the requirements of helicity for potent antibiotic action are much higher for the gram positive Staphylococcus.aureus than is the case with the Gram-negative Escherichia coli. In contrast, as shown in the present study, all dimers $\{(\Delta \mathrm{Fd}, \mathrm{Fd}, \mathrm{D}-\mathrm{Lys}-\Delta \mathrm{Fd}$, $\left.(\Delta \mathrm{Fm})_{2}\right\}$ are nearly equipotent against $P$. falciparum (Table 1). This suggests that different conformational and topological properties of peptides may be important for their activity against different organisms.

Some important features of these peptides as drugs against malaria include their favourable resistance indices (Table 1) that allow them to rapidly kill both drug-sensitive and drug-resistant strains of malaria parasite with equal potencies, their amphipathic nature that gives them drug-like character, and their ability to permeabilize and penetrate biological membranes, which allows them to attack target cells both from the surface as well as intracellularly. In addition, the presence of the conformationally constrained, non-protein, amino acid didehydrophenylalanine in both $\Delta \mathrm{Fd}$ and $(\Delta \mathrm{Fm})_{2}$ provides considerable protection against proteolytic degradation [25]. Even as these two dimeric peptides offer similar profiles of anti-plasmodial actions, a judicious choice for further improvisation should be the branched dimer $\Delta \mathrm{Fd}$ over the linear dimer $(\Delta \mathrm{Fm})_{2}$ since (a) the former is little more potent against $P$. falciparum, (b) the branched dimer is more stable against proteases [25], and (c) the branched dimer has better economics of production since the time it takes to synthesize a branched dimer is half as much as the time it takes to assemble a linear dimer.

\section{Conclusion}

This study reports the anti-plasmodial action of $\Delta \mathrm{Fd}$, a de novo-designed, cationic, lysine-branched amphipathic, helical peptide. In vitro assays suggest good selectivity (>35), good resistance index (1.1) and low mamamalian cell cytotoxicity, as a promise of $\Delta \mathrm{Fd}$ against malaria. The strategy adopted by $\Delta \mathrm{Fd}$ to inhibit the growth of malaria parasite appears to be broadly two-fold: (a) involving growth arrest without causing lysis of red cell (at $\mathrm{IC}_{50}-\mathrm{IC}_{100}$ ), and (b) anomalous egress of trophozoites and premature egress of undifferentiated schizonts leading to death of the parasite (at $\left.>\mathrm{IC}_{100}\right)$.

\section{Additional files}

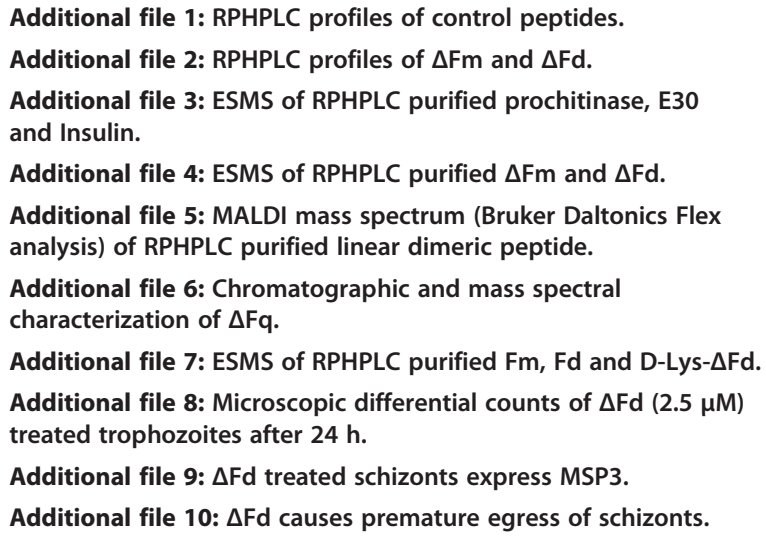

\section{Abbreviations}

$\mathrm{CQ}$ : Chloroquine; $\Delta \mathrm{F}$ : Didehydrophenylalanine; $\Delta \mathrm{Fm}: \Delta \mathrm{F}$ containing monomeric decapeptide; $\Delta \mathrm{Fd}$ : Lysine branched dimer of $\Delta \mathrm{Fm} ;(\Delta \mathrm{Fm})_{2}$ : Linear dimer of $\Delta$ Fm; DAPI: 4',6-diamidino-2-phenylindole; FACS: Fluorescence activated cell sorter; FITC: Fluorescein isothiocyanate;

P. falciparum: Plasmodium falciparum; $I C_{100}$ : Inhibitory concentration causing 100\% inhibition of growth; PRBC: Parasitized red blood cell; URBC: Uninfected red blood cell; Troph: Trophozoite; $\Delta \mathrm{Fq}$ :

The $\mathrm{K}-\mathrm{K}_{2}$ dendrimer presenting a quadrumer form of $\Delta \mathrm{Fm}$.

\section{Competing interests}

The authors declare that they have no competing interests.

\section{Authors' contributions}

NKK and JS carried out the experiments to determine the antiplasmodial potencies of different peptides, NKK performed mechanistic experiments including FACS and immunofluorescence microscopy, DS conceived of the study, participated in its design, coordination and brain storming and drafted the manuscript. All authors read and approved the final manuscript. 


\section{Acknowledgements}

We thank MR4 who generously provided the chloroquine-resistant Dd2 and INDO strains used in the study. Thanks to X Su and the late Dr. David Walliker who deposited these strains with MR4, BEl Resources Repository, NIAID, NIH: Our thanks to the anonymous reviewers for their critical and thoughtful comments that have enriched the manuscript enormously. We thank Dr. Pawan Malahotra for anti-band 3 antibody, Sumit Rathore for FACS analysis, Dr. Maryam Imam for providing anti MSP3 antibody, Dr. Aparna Anantharaman for MTT assay and Dr.Anil Sharma for help with statistical analysis. NKK thanks Indian Council for Medical Research (ICMR), New Delhi, for Senior Research fellowship. We thank the ICGEB, New Delhi for internal funding.

Received: 8 May 2012 Accepted: 13 July 2012

Published: 1 August 2012

\section{References}

1. Tinto H, Rwagacondo C, Karema C, Mupfasoni D, Vandoren W, Rusanganwa E, Erhart A, Van Overmeir C, Van Marck E, D'Alessandro U: In-vitro susceptibility of Plasmodium falciparum to monodesethylamodiaquine, dihydroartemisinin and quinine in an area of high chloroquine resistance in Rwanda. Trans R Soc Trop Med Hyg 2006, 100:509-514.

2. Mu J, Ferdig MT, Feng X, Joy DA, Duan J, Furuya T, Subramanian G, Aravind L, Cooper RA, Wootton JC, Xiong M, Su XZ: Multiple transporters associated with malaria parasite responses to chloroquine and quinine. Mol Microbiol 2003, 49:977-989.

3. Jacqueline R: Halt called on single-drug antimalarial prescriptions. Nature 2006, doi:10.1038/news060116-13.

4. Dondorp AM, Nosten F, Yi P, Das D, Phyo AP, Tarning J, Lwin KM, Ariey F, Hanpithakpong W, Lee SJ, Ringwald P, Silamut K, Imwong M, Chotivanich K, Lim P, Herdman T, An SS, Yeung S, Singhasivanon P, Day NP, Lindegardh N, Socheat D, White NJ: Artemisinin resistance in Plasmodium falciparum malaria. N Engl J Med 2009, 361:455-467.

5. White NJ: Artemisinin resistance--the clock is ticking. Lancet 2010, 376:2051-2052.

6. Crompton PD, Pierce SK, Miller LH: Advances and challenges in malaria vaccine development. J Clin Invest 2010, 120:4168-4178.

7. WHO: World Malaria Report 2011, Issue Dec. 2011. http://www.who.int/ mediacentre/factsheets/fs094/en/index.html.

8. Yount NY, Yeaman MR: Emerging themes and therapeutic prospects for anti-infective peptides. Annu Rev Pharmacol Toxicol 2012, 52:337-360.

9. Yeaman MR, Yount NY: Mechanisms of antimicrobial peptide action and resistance. Pharmacol Rev 2003, 55:27-55.

10. Epand RM, Shai Y, Segrest JP, Anantharamaiah GM: Mechanisms for the modulation of membrane bilayer properties by amphipathic helical peptides. Biopolymers 1995, 37:319-338.

11. Feder R, Dagan A, Mor A: Structure-activity relationship study of antimicrobial dermaseptin $\mathrm{S} 4$ showing the consequences of peptide oligomerization on selective cytotoxicity. J Biol Chem 2000, 275:4230-4238

12. Zasloff M: Antimicrobial peptides of multicellular organisms. Nature 2002, 415:389-395.

13. Sherman IW, Prudhomme J, Tait JF: Altered membrane phospholipid asymmetry in Plasmodium falciparum-infected erythrocytes. Parasitol Today 1997, 13:242-243.

14. Gelhaus C, Jacobs T, Andra J, Leippe M: The antimicrobial peptide NK-2, the core region of mammalian NK-lysin, kills intraerythrocytic Plasmodium falciparum. Antimicrob Agents Chemother 2008, 52:1713-1720

15. Ghosh JK, Shaool D, Guillaud P, Ciceron L, Mazier D, Kustanovich I, Shai Y, Mor A: Selective cytotoxicity of dermaseptin S3 toward intraerythrocytic Plasmodium falciparum and the underlying molecular basis. J Biol Chem 1997, 272:31609-31616.

16. Radzishevsky I, Krugliak M, Ginsburg H, Mor A: Antiplasmodial activity of lauryl-lysine oligomers. Antimicrob Agents Chemother 2007, 51:1753-1759.

17. Azouzi S, El Kirat K, Morandat S: The potent antimalarial drug cyclosporin A preferentially destabilizes sphingomyelin-rich membranes. Langmuir 2010, 26:1960-1965.

18. Boman HG, Wade D, Boman IA, Wahlin B, Merrifield RB: Antibacterial and antimalarial properties of peptides that are cecropin-melittin hybrids. FEBS Lett 1989, 259:103-106.
19. Gao B, Xu J: Rodriguez Mdel C, Lanz-Mendoza H, Hernandez-Rivas R, Du W, Zhu S: Characterization of two linear cationic antimalarial peptides in the scorpion Mesobuthus eupeus. Biochimie 2010, 92:350-359.

20. Nagaraj G, Uma MV, Shivayogi MS, Balaram H: Antimalarial activities of peptide antibiotics isolated from fungi. Antimicrob Agents Chemother 2001, 45:145-149.

21. Hancock RE, Sahl HG: Antimicrobial and host-defense peptides as new anti-infective therapeutic strategies. Nat Biotechnol 2006, 24:1551-1557.

22. Dathe $M$, Wieprecht T: Structural features of helical antimicrobial peptides: their potential to modulate activity on model membranes and biological cells. Biochim Biophys Acta 1999, 1462:71-87.

23. Giangaspero A, Sandri L, Tossi A: Amphipathic alpha helical antimicrobial peptides. Eur J Biochem 2001, 268:5589-5600.

24. Malina A, Shai Y: Conjugation of fatty acids with different lengths modulates the antibacterial and antifungal activity of a cationic biologically inactive peptide. Biochem J 2005, 390:695-702.

25. Dewan PC, Anantharaman A, Chauhan VS, Sahal D: Antimicrobial action of prototypic amphipathic cationic decapeptides and their branched dimers. Biochemistry 2009, 48:5642-5657.

26. Trager W, Jensen JB: Human malaria parasites in continuous culture. Science 1976, 193:673-675.

27. MR4. http://www.mr4.org/MR4ReagentsSearch/Results.aspx?BEINum=MRA819\&Template $=$ parasites

28. Lambros C, Vanderberg JP: Synchronization of Plasmodium falciparum erythrocytic stages in culture. J Parasitol 1979, 65:418-420.

29. Rivadeneira EM, Wasserman M, Espinal CT: Separation and concentration of schizonts of Plasmodium falciparum by Percoll gradients. J Protozool 1983, 30:367-370

30. Smilkstein M, Sriwilaijaroen N, Kelly JX, Wilairat P, Riscoe M: Simple and inexpensive fluorescence-based technique for high-throughput antimalarial drug screening. Antimicrob Agents Chemother 2004, 48:1803-1806.

31. Mosmann T: Rapid colorimetric assay for cellular growth and survival: application to proliferation and cytotoxicity assays. J Immunol Meth 1983, 65:55-63.

32. Yonath A: Polar bears, antibiotics, and the evolving ribosome (Nobel Lecture). Angew Chem Int Ed Engl 2010, 49:4341-4354.

33. Matsuzaki K: Why and how are peptide-lipid interactions utilized for self-defense? Magainins and tachyplesins as archetypes. Biochim Biophys Acta 1999, 1462:1-10.

34. Shai Y: Mechanism of the binding, insertion and destabilization of phospholipid bilayer membranes by alpha-helical antimicrobial and cell non-selective membrane-lytic peptides. Biochim Biophys Acta 1999, 1462:55-70.

35. Yang L, Weiss TM, Lehrer RI, Huang HW: Crystallization of antimicrobial pores in membranes: magainin and protegrin. Biophys J 2000, 79:2002-2009.

36. Ramagopal UA, Ramakumar S, Mathur P, Joshi R, Chauhan VS: Dehydrophenylalanine zippers: strong helix-helix clamping through a network of weak interactions. Protein Eng 2002, 15:331-335.

37. Ramagopal UA, Ramakumar S, Sahal D, Chauhan VS: De novo design and characterization of an apolar helical hairpin peptide at atomic resolution: Compaction mediated by weak interactions. Proc Natl Acad Sci U S A 2001, 98:870-874.

38. Rudresh, Ramakumar S, Ramagopal UA, Inai Y, Goel S, Sahal D, Chauhan VS: De novo design and characterization of a helical hairpin eicosapeptide; emergence of an anion receptor in the linker region. Structure 2004, 12:389-396.

39. Fichera ME, Roos DS: A plastid organelle as a drug target in apicomplexan parasites. Nature 1997, 390:407-409.

40. Ralph SA, D'Ombrain MC, McFadden GI: The apicoplast as an antimalarial drug target. Drug Resist Updat 2001, 4:145-151.

41. Dahl EL, Rosenthal PJ: Multiple antibiotics exert delayed effects against the Plasmodium falciparum apicoplast. Antimicrob Agents Chemother 2007, 51:3485-3490.

42. Hanssen E, McMillan PJ, Tilley L: Cellular architecture of Plasmodium falciparum-infected erythrocytes. Int J Parasitol 2010, 40:1127-1135.

43. Allred DR, Sterling CR, Morse PD 2nd: Increased fluidity of Plasmodium berghei-infected mouse red blood cell membranes detected by electron spin resonance spectroscopy. Mol Biochem Parasitol 1983, 7:27-39.

44. Howard RJ, Sawyer WH: Changes in the membrane microviscosity of mouse red blood cells infected with Plasmodium berghei detected 
using $\mathrm{n}$-(9-anthroyloxy) fatty acid fluorescent probes. Parasitology 1980, 80:331-342.

45. Sherman IW, Greenan JR: Altered red cell membrane fluidity during schizogonic development of malarial parasites (Plasmodium falciparum and P. lophurae). Trans R Soc Trop Med Hyg 1984, 78:641-644.

46. Taraschi TF, Parashar A, Hooks M, Rubin H: Perturbation of red cell membrane structure during intracellular maturation of Plasmodium falciparum. Science 1986, 232:102-104.

47. Vial HJ, Philippot JR, Wallach DF: A reevaluation of the status of cholesterol in erythrocytes infected by Plasmodium knowlesi and P. falciparum. Mol Biochem Parasitol 1984, 13:53-65.

48. Vial HJ, Thuet MJ, Broussal JL, Philippot JR: Phospholipid biosynthesis by Plasmodium knowlesi-infected erythrocytes: the incorporation of phospohlipid precursors and the identification of previously undetected metabolic pathways. J Parasitol 1982, 68:379-391.

49. Gupta CM, Mishra GC: Transbilayer phospholipid asymmetry in Plasmodium knowlesi-infected host cell membrane. Science 1981, 212:1047-1049.

50. Joshi P, Dutta GP, Gupta CM: An intracellular simian malarial parasite (Plasmodium knowlesi) induces stage-dependent alterations in membrane phospholipid organization of its host erythrocyte. Biochem J 1987, 246:103-108.

51. Schwartz RS, Olson JA, Raventos-Suarez C, Yee M, Heath RH, Lubin B, Nagel RL: Altered plasma membrane phospholipid organization in Plasmodium falciparum-infected human erythrocytes. Blood 1987, 69:401-407.

52. Ginsburg H, Kutner S, Zangwil M, Cabantchik Zl: Selectivity properties of pores induced in host erythrocyte membrane by Plasmodium falciparum. Effect of parasite maturation. Biochim Biophys Acta 1986, 861:194-196.

53. Kutner S, Ginsburg H, Cabantchik Zl: Permselectivity changes in malaria (Plasmodium falciparum) infected human red blood cell membranes. J Cell Physiol 1983, 114:245-251.

54. Vial HJ, Ancelin ML: Malarial lipids. An overview. Subcell Biochem 1992, 18:259-306

55. Wender PA, Mitchell DJ, Pattabiraman K, Pelkey ET, Steinman L, Rothbard JB: The design, synthesis, and evaluation of molecules that enable or enhance cellular uptake: peptoid molecular transporters. Proc Natl Acad Sci U S A 2000, 97:13003-13008

56. Rothbard JB, Jessop TC, Lewis RS, Murray BA, Wender PA: Role of membrane potential and hydrogen bonding in the mechanism of translocation of guanidinium-rich peptides into cells. J Am Chem Soc 2004, 126:9506-9507.

57. Terrone D, Sang SL, Roudaia L, Silvius JR: Penetratin and related cellpenetrating cationic peptides can translocate across lipid bilayers in the presence of a transbilayer potential. Biochemistry 2003, 42:13787-13799.

58. Brown KL, Conboy JC: Electrostatic induction of lipid asymmetry. J Am Chem Soc 2011, 133:8794-8797.

doi:10.1186/1475-2875-11-256

Cite this article as: Kaushik et al:: Anti-plasmodial action of de novo-designed, cationic, lysine-branched, amphipathic, helical peptides. Malaria Journal 2012 11:256.

\section{Submit your next manuscript to BioMed Central and take full advantage of:}

- Convenient online submission

- Thorough peer review

- No space constraints or color figure charges

- Immediate publication on acceptance

- Inclusion in PubMed, CAS, Scopus and Google Scholar

- Research which is freely available for redistribution

Submit your manuscript at www.biomedcentral.com/submit
( Biomed Central 